\title{
Comparison of crystal field dependent and independent methods to analyse lanthanide induced NMR shifts in axially symmetric complexes. Part I. Systems with a $C_{3}$ symmetry axis
}

\author{
Carlos F.G.C. Geraldes ${ }^{a, b, *}$, Shanrong Zhang ${ }^{c}$, A. Dean Sherry ${ }^{c, d}$ \\ a Department of Biochemistry, Faculty of Science and Technology, University of Coimbra, P.O. Box 3126, Coimbra 3001-401, Portugal \\ ${ }^{\mathrm{b}}$ Center of Neurosciences, Faculty of Science and Technology, University of Coimbra, P.O. Box 3126, Coimbra 3001-401, Portugal \\ ${ }^{\mathrm{c}}$ Department of Chemistry, The University of Texas at Dallas, P.O. Box 830688, Richardson, TX 75083-0688, USA \\ ${ }^{\mathrm{d}}$ The Mary Nell and Ralph B. Rogers Magnetic Resonance Center, Department of Radiology, University of Texas Southwestern Medical Center. \\ 5801 Forest Park Rd., Dallas, TX 75235-9085, USA
}

Received 4 December 2002; accepted 24 March 2003

\begin{abstract}
A critical analysis of the lanthanide induced paramagnetic shift (LIS) data for several series of $\mathrm{Ln}^{3+}$ complexes of $C_{3}$ symmetry in terms of structural changes, crystal-field effects and/or variation of hyperfine constants along the lanthanide series was undertaken using a combination of the two-nuclei and three-nuclei techniques together with the classical one-nucleus technique. The crystal-field independent two-nuclei technique to study the isostructurality of a series of lanthanide complexes, is usefully complemented by the three nuclei shift ratio method, which is based exclusively on the experimental shift data, requiring no knowledge of $B_{0}^{2},\left\langle S_{z}\right\rangle$ or $C_{j}$ values. However, this later method cannot provide quantitative values for $F_{i}$ and $G_{i}$. The combined use of the three methods was found to be a powerful analytical tool of the solution structure of lanthanide complexes. Isostructurality of whole series of complexes, either with no change of the $F_{i}, G_{i}$ and $B_{0}^{2}$ parameters $\left(\mathrm{L}^{5}\right.$ and $\left.\mathrm{L}^{6}\right)$, or with changes of the $F_{i}$ and $B_{0}^{2}$ parameters $\left(\mathrm{L}^{7}\right.$ and $\left.\mathrm{L}^{8}\right)$, is clearly defined by the combination of the two first methods. In these cases, the three-nuclei method sometimes fully supports such an isostructurality $\left(\mathrm{L}^{6}, \mathrm{~L}^{8}\right)$, but in other cases, due to the high structural sensitivity of its $\alpha$ and $\beta$ parameters, it is able to detect small, unnoticed, structural changes in the complexes of $\mathrm{L}^{5}$ and $\mathrm{L}^{7}$. Clear structural changes, involving the $F_{i}$, $G_{i}$ and $B_{0}^{2}$ parameters, are observed for the series of complexes of $\left(\mathrm{L}^{9}\right)$, where the three methods agree, involving hydration and carboxylate coordination changes. More subtle structural changes, involving the internal dynamics of the bound ligands, are proposed in other cases $\left(\mathrm{L}^{1}-\mathrm{L}^{4}\right)$. These could also result from a magnification, by the present graphical analysis, of the breaks expected from the gradual structural changes along the series due to the lanthanide contraction.
\end{abstract}

(C) 2003 Elsevier B.V. All rights reserved.

Keywords: Solution structure by NMR; Lanthanide complexes; Lanthanide induced shifts

\section{Introduction}

Paramagnetic trivalent lanthanide metal ions, $\mathrm{Ln}^{3+}$, are ideal structural probes in supramolecular complexes and in proteins [1]. The coupling of the electronic magnetic moment of the metal ion with the magnetic moments of the ligand nuclei enhances nuclear relaxation processes

\footnotetext{
${ }^{*}$ Corresponding author. Tel.: +351-23982-4531; fax: +351-239853607.

E-mail address: geraldes@ci.uc.pt (C.F.G.C. Geraldes).
}

and induces large hyperfine NMR chemical shifts via contact (through-bond) and pseudo-contact (throughspace) mechanisms [2]. Lanthanide induced nuclear relaxation (LIR) effects provide useful structural information through Ln-nucleus distances [3] and water solvent relaxation enhancements induced by $\mathrm{Gd}(\mathrm{III})$ complexes have found very useful biomedical applications as contrast agents for Magnetic Resonance Imaging [4]. The observed lanthanide-induced shifts (LIS) have magnitudes and signs depending critically on both the nature of the $\mathrm{Ln}^{3+}$ ion and the location of the nucleus 
relative to the metal center, making them very sensitive to structural changes associated with changes in $\mathrm{pH}$, temperature and counter-ions [5]. This unique feature allows the lanthanide complexes to be used for many purposes, such as elucidation of molecular conformation [6], resolution of enantiomers [7], simplification of NMR spectra [8], separation of transmembrane cation resonances [9], determination of water coordination numbers of lanthanide complexes [10], investigation of the coordination state of lanthanide ions [11] and design of temperature probes in biological systems [12].

The observed paramagnetic LIS values, $\delta_{i j}^{\text {para }}$, induced by a paramagnetic $\mathrm{Ln}^{3+}$ ion $j$ upon the NMR signal of a nucleus $i$ has two contributions [13-17], a Fermi contact $\left(\delta_{i j}^{\mathrm{c}}\right)$ and dipolar or pseudo-contact shift $\left(\delta_{i j}^{\mathrm{d}}\right)$, which in an axially symmetric complex (with at least a $C_{3}$ or $C_{4}$ symmetry axis) [18] can be written as

$\delta_{i j}^{\mathrm{para}}=\delta_{i j}^{\mathrm{c}}+\delta_{i j}^{\mathrm{d}}=F_{i}\left\langle S_{z}\right\rangle_{j}+C_{j} B_{2}^{0} G_{i}$,

where the contact contribution is the product of $F_{i}$, which is proportional to the hyperfine coupling constant $A_{i}$ of the ligand nucleus, and the spin expectation value $\left\langle S_{z}\right\rangle_{j}$ for the paramagnetic $\mathrm{Ln}^{3+}$, while the dipolar shift is the product of the magnetic constant $C_{j}$ measuring at a given temperature the second-order magnetic axial anisotropy of the paramagnetic lanthanide $j$ (Bleaney's factor scaled to -100 for Dy), the axial second-order crystal field parameter of the complex $B_{2}^{0}$, and the axial geometric factor $G_{i}\left[G_{i}=\left(3 \cos ^{2} \theta_{i}-1\right) / r_{i}^{3}\right]$ of nucleus $i$, where $r_{i}$ and $\theta_{i}$ are the axial polar coordinates of nucleus $i$ in the principal axis $z$-axis of the magnetic susceptibility tensor of the complex, with the $\mathrm{Ln}^{3+}$ ion at the origin. Since the dipolar term contains the geometric information of interest, any quantitative structural analysis requires a reliable separation of the observed shift into the contact and dipolar terms. An empirical separation method has been proposed [19] based on measurement of LIS data for a series of lanthanide complexes. The LIS separation is then achieved at a fixed temperature based on the following assumptions: (1) the $\left\langle S_{z}\right\rangle_{j}$ and $C_{j}$ parameters tabulated for the $\mathrm{Ln}^{3+}$ free ions $[13,15,20]$ are a valid approximation for all complexes; (2) the hyperfine coupling constants $\left(A_{i}\right.$, and hence the $F_{i}$ terms) for each nucleus, and the crystal field parameter, $B_{2}^{0}$, are invariant along the lanthanide series. This one-nucleus technique uses plots based on rearrangement of Eq. (1) into two linear forms (Eqs. (2) and (3))

$\frac{\delta_{i j}^{\text {para }}}{\left\langle S_{z}\right\rangle_{j}}=F_{i}+B_{2}^{0} G_{i} \frac{C_{j}}{\left\langle S_{z}\right\rangle_{j}}$,

$\frac{\delta_{i j}^{\text {para }}}{C_{j}}=F_{i} \frac{\delta_{i j}^{\text {para }}}{\left\langle S_{z}\right\rangle_{j}}+B_{2}^{0} G_{i}$.

Often plots of the observed LIS data according to Eqs. (2) and (3) are linear for the entire lanthanide se- ries. Then, $F_{i}$ and $\left(B_{2}^{0} G_{i}\right)$ can be determined by linear regression and the above assumptions are proven to be valid, in particular that the geometric factors, $G_{i}$, for each nucleus do not change for the various $\mathrm{Ln}^{3+}$ complexes of the ligand studied (isostructural complexes) and the crystal field coefficient is invariant along the $\mathrm{Ln}^{3+}$ series. However, frequent breaks have been found to occur in such plots near the middle of the Ln series (Gd-Dy) [2b,2c,11b]. Such deviations have sometimes been ascribed [21] to the lanthanide contraction (ionic radii of the $\mathrm{Ln}^{3+}$ ions decrease across the series from 1.36 to $1.17 \AA$ ), which gradually alters the $G_{i}$ factors, an effect which is amplified for the heavier lanthanides because of their large $C_{j}$ values [14]. However, such breaks could also arise form variations of $F_{i}$ and/or the crystal field parameter $B_{2}^{0}$ along the Ln series [22-24]. We have recently shown for $[\operatorname{Ln}(\mathrm{DOTP})]^{5-}$ complexes that the crystal field parameter $B_{2}^{0}$ indeed changes along the later half of lanthanide series $(\mathrm{Tb}-\mathrm{Yb})$ with a maximum observed for $\mathrm{Tm}^{3+}$ [23]. Although ${ }^{23} \mathrm{Na}$ NMR shifts induced by the $\left[\mathrm{Ln}(\mathrm{DOTP}]^{5-}\right.$ complexes do not uniformly correlate with Bleaney's factors $C_{j}$, they do correlate well with the product $B_{2}^{0} C_{j}$. The axial $\mathrm{D}_{1}\left(=B_{2}^{0} C_{j}\right)$ and rhombic $\mathrm{D}_{2}\left(=B_{2}^{2} C_{j}\right)$ magnetic constants found for $\mathrm{Ln}-$ texaphyrin complexes also could not be reasonably correlated to Bleaney's $C_{j}$ values, again indicating an irregular change of the crystal field parameters along the $\mathrm{Ln}^{3+}$ series [24].

Based on previous work [22], consideration the paramagnetic shifts $\delta_{i j}^{\text {para }}$ and $\delta_{k j}^{\text {para }}$ of two nuclei $i$ and $j$ of the same complex allows the removal of the crystal field parameter $B_{2}^{0}$, leading to Eq. (4), which can be used to investigate isostructurality of complexes along the lanthanide series [25]

$\frac{\delta_{i j}^{\text {para }}}{\left\langle S_{z}\right\rangle_{j}}=\left(F_{i}-F_{k} R_{i k}\right)+R_{i k} \frac{\delta_{k j}^{\text {para }}}{\left\langle S_{z}\right\rangle_{j}}$,

where $R_{i k}=G_{i} / G_{k}$. Since Eq. (4) does not depend on the crystal field parameter, any deviation from linearity found on plots of $\delta_{i j}^{\text {para }} /\left\langle S_{z}\right\rangle_{j}$ versus $\left.\left.\delta_{k j}^{\text {para }} /\right\rangle S_{z}\right\rangle_{j}$ along the Ln series can be safely ascribed to structural changes affecting $R_{i k}$, and thus $G_{i}$ and $G_{k}$ [25-27].

Although $\left\langle S_{z}\right\rangle_{j}$ is relatively independent from crystal field effects around room temperature, there have been some differences in the calculated $\left\langle S_{z}\right\rangle_{j}$ values reported, especially for the lighter lanthanide ions $[14,16]$. Furthermore, it is sometimes desirable to measure LIS values at low or high temperature in order to avoid inter- or intramolecular exchange problems. However, there is a paucity of reliable theoretical $\left\langle S_{z}\right\rangle$ and $C_{j}$ values for either abnormally high or low temperatures, and there has been inconsistency in the literature about the temperature dependence of the dipolar shift for some of the lanthanide ions, in particular for $\mathrm{Sm}$ and $\mathrm{Eu}[17,18$, $20,28]$. Thus, it would be highly desirable to analyze 
LIS data and to test for isostructurality of series of lanthanide complexes without recourse to the use of both the crystal field parameter of the complexes and the theoretical $\left\langle S_{z}\right\rangle_{j}$ and $C_{j}$ free-ion parameters. This can be achieved with a three-nuclei method, recently proposed by us [29], based on Eq. (5) for three different nuclei $i, k$, $l$ in the same lanthanide complex

$\frac{\delta_{i j}^{\text {para }}}{\delta_{k j}^{\text {para }}}=\alpha \frac{\delta_{l j}^{\text {para }}}{\delta_{k j}^{\text {para }}}+\beta$,

where $\left.\left.\alpha=\left[\left(F_{i} / F_{k}\right)-R_{i k}\right)\right] /\left[\left(F_{l} / F_{k}\right)-R_{l k}\right)\right]$ and $\beta=\left[\left(F_{l} /\right.\right.$ $\left.\left.F_{k}\right) R_{i k}-\left(F_{i} / F_{k}\right) R_{l k}\right] /\left[\left(F_{l} / F_{k}\right)-R_{l k}\right]$. According to Eq. (5), plots of $\left(\delta_{i j}^{\text {para }} / \delta_{k j}^{\text {para }}\right)$ versus $\left(\delta_{i j}^{\text {para }} / \delta_{i j}^{\text {para }}\right)$ for a series of lanthanide complexes are expected to be linear, with slope $\alpha$ and intercept $\beta$, provided that the complexes are isostructural and the hyperfine coupling constants are invariant along the lanthanide series. This method is extremely flexible in that data may be collected over a very wide range of temperatures. It is solely based on experimental LIS data and can be applied to any ligand for which the LIS data are available for at least three nuclei.

Further information about the structure of the complexes is provided by the experimental relative $\mathrm{Ln}-\mathrm{H}_{j}$ distance values $\left(r_{\mathrm{H} j}\right)$, obtained from the paramagnetic proton relaxation times, $T_{i}$, by the following equation [2]:

$r_{\mathrm{H} j} / r_{\mathrm{H} k}=\left(T_{i, \mathrm{H} k} / T_{i, \mathrm{H} j}\right)^{1 / 6}, \quad i=1,2$.

The relative distances obtained by Eq. (6) should be independent of the electronic spin relaxation time, rotational correlation time and magnetic moment of each individual complex.

The combined use of the above two-nuclei and threenuclei techniques together with the classical one-nucleus technique, according to Eqs. (1)-(5), to study the LIS values for a series of lanthanide complexes, is particularly powerful in assigning eventual structural changes, crystal-field effects and/or variation of hyperfine constants along the lanthanide series. This approach has been described for a series of $C_{3}$-axial Ln-cryptate complexes in water $\left[\mathrm{Ln}\left(\mathrm{L}^{8}\right)\right]^{3+}$, where $\mathrm{L}^{8}$ is an azacryptand (Fig. 1), with unequivocal proof of abrupt changes of the $F_{i}$ and $B_{2}^{0}$ parameters at $\mathrm{Ln}=\mathrm{Eu}-\mathrm{Tb}$, but the constancy of the geometric ratios $R_{i k}$ showed the isostructurality of the whole series of complexes [26,29]. A similar study has been recently undertaken for ${ }^{13} \mathrm{C}$ and ${ }^{1} \mathrm{H}$ LIS in the $D_{3}$-symmetrical triple helical series of<smiles>O=C(O)CO</smiles><smiles>CCN(CC)C(=O)c1cccc(C(=O)N(CC)CC)n1</smiles><smiles>[R]n1c(-c2cccc(-c3nc4ccccc4n3[R])n2)nc2ccccc21</smiles>

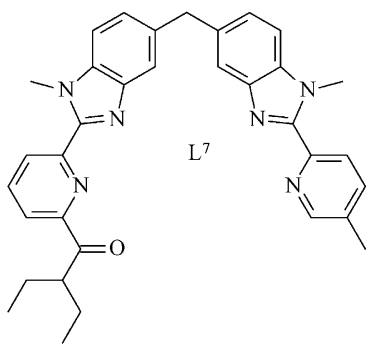<smiles>O=C(O)c1cc(O)cc(C(=O)O)n1</smiles><smiles>c1ccc(-c2cccc(-c3ccccn3)n2)nc1</smiles>

$\mathrm{L}^{6}$

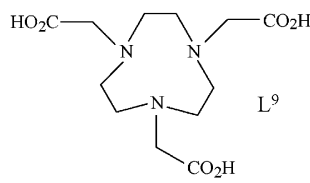

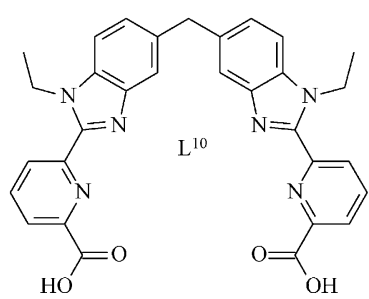

Fig. 1. Chemical structure of the ligands cited in this work. 
$\left[\mathrm{Ln}\left(\mathrm{L}^{3}-2 \mathrm{H}\right)_{3}\right]^{3-}$ complexes in water $\left(\mathrm{L}^{3}-2 \mathrm{H}=\right.$ dipicolinate $=$ pyridine-2,6-dicarboxylate) (see Fig. 1) [30]. The combination of the one-nucleus and two-nuclei techniques has been applied to the analysis of the LIS data for other monometallic and bimetallic triple-stranded helicates [31,32]. The monometallic $D_{3}$-symmetrical complexes $\left[\operatorname{Ln}\left(\mathrm{L}^{4}\right)_{3}\right]^{3+}$ show breaks at Dy-Er in both types of plots, indicating a structural change along the lanthanide series, with variations of $F_{i}$ and $B_{2}^{0}$ parameters [31]. For the $C_{3}$-symmetrical triple-stranded helicates $\left[\mathrm{LnCo}\left(\mathrm{L}^{7}\right)_{3}\right]^{5 / 6+}$ and $\left[\operatorname{Ln}_{2}\left(\mathrm{~L}^{10}-2 \mathrm{H}\right)_{3}\right]$, in which the $\mathrm{Ln}^{3+}$ are firmly held in rigid nine-coordinate tricapped trigonal prismatic sites, abrupt variations of the $F_{i}$ and $B_{2}^{0}$ parameters have been observed near the middle of the series, with no structural variations involved [31,32].

The power of the above described combined use of the two-nuclei and three-nuclei techniques together with the classical one-nucleus technique in the critical analysis of LIS data in terms of structural changes, crystalfield effects and/or variation of hyperfine constants along the lanthanide series, leads us to extend this approach to systematically examine in this work a collection of LIS data already reported in the literature using only data from slow exchanging complexes with sterically rigid ligands. In this first contribution, a series $\mathrm{Ln}^{3+}$ complexes having threefold symmetry (at least a $C_{3}$ axis) was examined, including cases with linear, macrocyclic and aromatic ligands in several different stoichiometries, solvents and temperatures (Fig. 1).

\section{Results and discussion}

\section{1. $\left[\operatorname{Ln}(G L Y C)_{3}\right]\left(L^{1}=\right.$ glycolic acid, $\left.G L Y C\right)$}

Glycolate $\left(\mathrm{L}^{1}-\mathrm{H}\right)$ forms 3:1 complexes with $\mathrm{Ln}^{3+}$ cations of reasonable overall stability $\log \beta_{3}=$ 10.25-13.36 [33]. However, due to the limited thermodynamic stability of the $\left[\operatorname{Ln}(\mathrm{GLYC})_{3}\right]$ complexes in aqueous solution relative to the $1: 1$ and $1: 2$ species [33], the corresponding experimental ${ }^{1} \mathrm{H},{ }^{13} \mathrm{C}$ and ${ }^{17} \mathrm{O} \mathrm{NMR}$ shifts for the bound ligands in the $\left[\mathrm{Ln}(\mathrm{GLYC})_{3}\right]$ complexes $(\mathrm{Ln}=\mathrm{La}-\mathrm{Lu}$, except $\mathrm{Pm}$ and $\mathrm{Gd})$ were obtained by extrapolation from fast-exchange spectra at $\mathrm{pD}=4.5$ and $346 \mathrm{~K}$ [34]. The corresponding calculated paramagnetic shifts, $\delta_{i j}^{\text {para }}$, led to the conclusion that the $3: 1$ species in solution is formulated as $\left[\mathrm{Ln}(\mathrm{GLYC})_{3}\left(\mathrm{H}_{2} \mathrm{O}\right)_{3}\right]$ [34]. Plots of $\delta_{i j}^{\text {para }} /\left\langle S_{z}\right\rangle_{j}$ versus $C_{j} /\left\langle S_{z}\right\rangle_{j}$ (Eq. (2)) and $\delta_{i j}^{\text {para }} / C_{j}$ versus $\left\langle S_{z}\right\rangle_{j} / C_{j}$ (Eq. (3)) along the lanthanide series were obtained for $\left[\mathrm{Ln}(\mathrm{GLYC})_{3}\left(\mathrm{H}_{2} \mathrm{O}\right)_{3}\right]$ and were considered linear, leading to the conclusion that these complexes are isostructural [34]. With the assumption that these complexes have $C_{3}$ symmetry, a fit of the axial geometric factors $G_{i}$ with the equation $G_{i}=\left(3 \cos ^{2} \theta_{i}-\right.$ 1) $/ r_{i}^{3}$ gave an optimum for a model in which the $\operatorname{Ln}^{3+}$ coordination polyhedron is a tricapped trigonal prism, with the carboxylate oxygens at the capping positions and the other oxygens (hydroxyl and water) at the prismatic positions, a geometry very similar to that of the ODA and PDCA complexes (see later) [34]. Such a bidentate binding of glycolate to the $\mathrm{Ln}^{3+}$ via one of the carboxylate oxygens and the hydroxyl oxygen was confirmed by Dy(III) induced water ${ }^{17} \mathrm{O}$ shift measurements [35] and $\mathrm{Gd}(\mathrm{III})$ induced ${ }^{13} \mathrm{C}$ relaxation rate enhancements [36].

However, a close analysis of the plots obtained according to Eqs. (2) and (3) leads to a somewhat different conclusion. While for the ${ }^{17} \mathrm{O}$ shifts, both plots define good linear correlations without any break (although the data for $\mathrm{Ce}$ is out of line for the ${ }^{17} \mathrm{O}$ hydroxyl resonance), the plots for the $\mathrm{CH}_{2}{ }^{13} \mathrm{C}$ and ${ }^{1} \mathrm{H}$ resonances ( $\mathrm{CH}_{2}$ and $\mathrm{CH}_{2}$, respectively) according to Eq. (2) show the presence of small breaks and are linear according to Eq. (3), while the ${ }^{13} \mathrm{C}$ carboxylate $C_{\mathrm{o}}$ resonance gives large breaks with both Eqs. (2) and (3) (Fig. 2). The presence of small breaks in plots according to Eq. (2) and their absence in plots according to Eq. (3) is usually ascribed to small structural changes of the complexes resulting from the lanthanide contraction [21]. Our observation of two unambiguous linear correlations in some of these plots, with an abrupt break near the middle of the series, is clear indication that the $F_{i}$ and
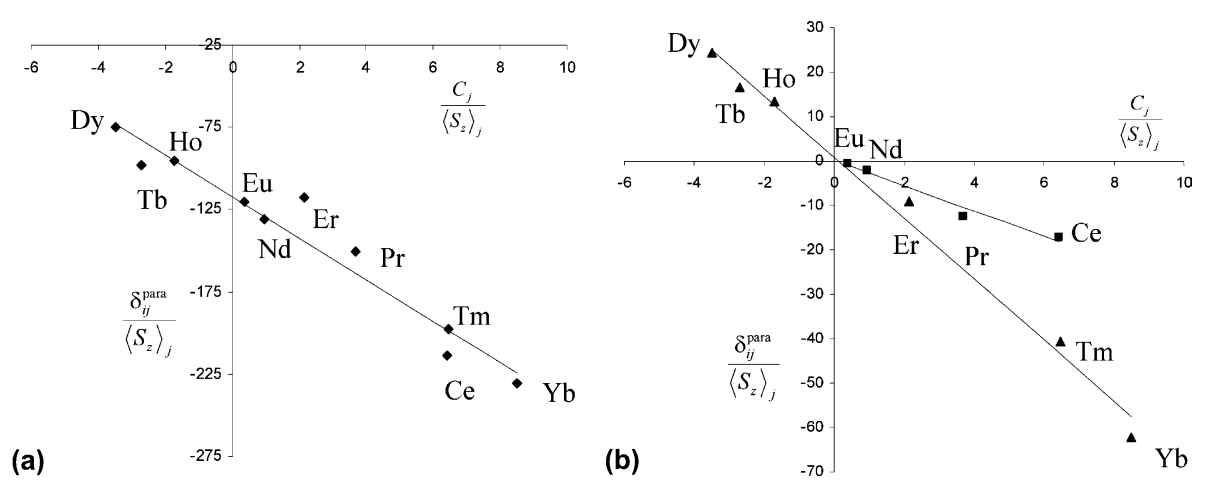

Fig. 2. Plots of $\delta_{i j}^{\text {para }} /\left\langle S_{z}\right\rangle_{j}$ vs. $C_{j} /\left\langle S_{z}\right\rangle_{j}$ along the lanthanide series for various nuclei of $\left[\operatorname{Ln}(\mathrm{GLYC})_{3}\left(\mathrm{H}_{2} \mathrm{O}\right)_{3}\right]\left(\mathrm{D}_{2} \mathrm{O}, \mathrm{pD}=4.5,346 \mathrm{~K}\right):(\mathrm{a}){ }^{17} \mathrm{O}$ and $(\mathrm{b})$

${ }^{13} \mathrm{C}$ nuclei, both of the carboxylate group. 
$B_{0}^{2} G_{i}$ parameters vary from $(\mathrm{Ce}-\mathrm{Eu})$ to $(\mathrm{Tb}-\mathrm{Yb})$, but the presence a structural change may be hidden by any change of the crystal-field parameter $B_{0}^{2}$.

Further analysis of the data using the crystal-field independent two-nuclei technique (Eq. (4)), led to various plots of $\delta_{i j}^{\text {para }} /\left\langle S_{z}\right\rangle_{j}$ versus $\delta_{k j}^{\text {para }} /\left\langle S_{z}\right\rangle_{j}$ for $j=\mathrm{Ce}-\mathrm{Yb}$. These plots are approximately linear when $i$ is an ${ }^{17} \mathrm{O}$ nucleus (e.g. $i={ }^{17} \mathrm{OH}, k=C_{\mathrm{o}}$, Fig. 3a), but show clear breaks at $\mathrm{Eu} / \mathrm{Tb}$ for ${ }^{1} \mathrm{H}$ and ${ }^{13} \mathrm{C}$ data (e.g. $i=\mathrm{CH}_{2}$, and $k=C_{\mathrm{o}}, i=\mathrm{CH}_{2}$ and $k=C_{\mathrm{o}}$ (Fig. 3b), displaying two different, non-parallel straight lines for $(\mathrm{Ce}-\mathrm{Eu})$ and ( $\mathrm{Tb}-\mathrm{Yb})$. The two sets of complexes have different $R_{i k}$ and $F_{i}$ parameter values, resulting from a structural change along the series of complexes, independently of any change of the crystal field parameter.

Plots of $\delta_{i j}^{\text {para }} / \delta_{k j}^{\text {para }}$ versus $\delta_{l j}^{\text {para }} / \delta_{k j}^{\text {para }}$ according to the three-nuclei method (Eq. (5)) also give different results depending on the nuclei chosen. When nuclei that give no breaks or very small breaks in the plots of the onenucleus method are chosen, the plots obtained also do not show any break, e.g. $i={ }^{17} \mathrm{O}-\mathrm{OH}, k={ }^{13} \mathrm{C}-\mathrm{CH}_{2}$ and $l={ }^{17} \mathrm{O}-\mathrm{CO}$ (Fig. 4a). However, the plots involving the
${ }^{13} \mathrm{C} \mathrm{CH}_{2}$ nucleus, which gives a large break in the plots of the one-nucleus method, also show clear breaks, e.g. $i={ }^{17} \mathrm{O}-\mathrm{OH}, k={ }^{13} \mathrm{C}-\mathrm{CH}_{2}$ and $l={ }^{17} \mathrm{O}-C_{\mathrm{o}}, i={ }^{13} \mathrm{C}-C_{\mathrm{o}}$, $k={ }^{13} \mathrm{C}-\mathrm{CH}_{2}, \quad l={ }^{1} \mathrm{H}-\mathrm{CH}_{2}$, and $\quad i={ }^{17} \mathrm{O}-\mathrm{CO}, \quad k=$ ${ }^{13} \mathrm{C}-\mathrm{CH}_{2}, l={ }^{13} \mathrm{C}-\mathrm{C}_{\mathrm{o}}$, confirming the structural break occurring near the middle of the series. In one of the later plots (Fig. 4b) two approximately parallel lines are obtained (for $\mathrm{Ln}=\mathrm{Ce}-\mathrm{Eu}$ and $\mathrm{Ln}=\mathrm{Tb}-\mathrm{Yb}$ ) with nearly the same slope $\alpha$ and different intercepts $\beta$, which depend on the values of the $F_{i}$ and $G_{i}$ parameters.

\section{2. $\left[\operatorname{Ln}(O D A)_{3}\right]^{3-}\left(L^{2}=\right.$ oxydiacetic acid, $\left.O D A\right)$}

The limited thermodynamic stability of the [ $\mathrm{Ln}$ $\left.(\mathrm{ODA})_{3}\right]^{3-}$ complexes in aqueous solution relative to the $1: 1$ and $1: 2$ species [33] made it necessary to obtain the corresponding experimental ${ }^{1} \mathrm{H}$ and ${ }^{13} \mathrm{C}$ NMR paramagnetic shifts for bound ligands $\delta_{i j}^{\text {para }}(\mathrm{Ln}=\mathrm{La}-$ $\mathrm{Lu}$, except $\mathrm{Pm}$ and $\mathrm{Gd}$ for ${ }^{1} \mathrm{H}$ and ${ }^{13} \mathrm{C}$ and also $\mathrm{Ho}$ and $\mathrm{Tm}$ for ${ }^{1} \mathrm{H}$ ) by extrapolation from fast-exchange spectra at $346 \mathrm{~K}$ [37]. The formation of $D_{3}$-symmetrical triplehelical $\left[\mathrm{Ln}(\mathrm{ODA})_{3}\right]^{3-}$ complexes in solution agrees with

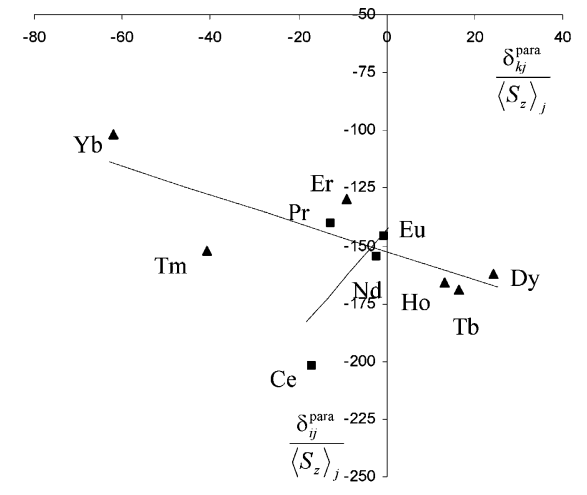

(a)

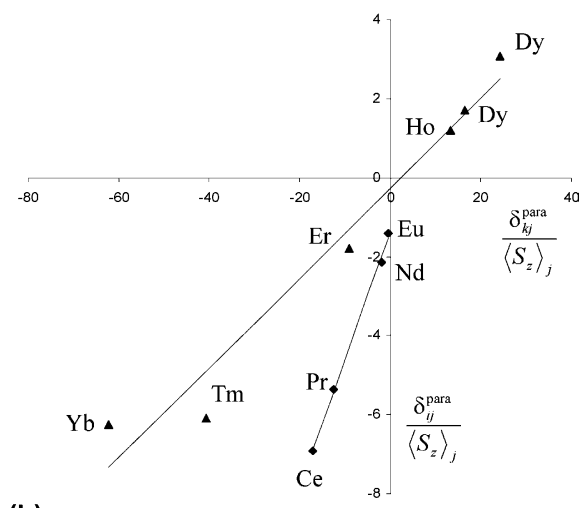

(b)

Fig. 3. Plots of $\delta_{i j}^{\text {para }} /\left\langle S_{z}\right\rangle_{j}$ vs. $\delta_{k j}^{\text {para }} /\left\langle S_{z}\right\rangle_{j}$ along the series of $\left[\mathrm{Ln}(\mathrm{GLYC})_{3}\left(\mathrm{H}_{2} \mathrm{O}\right)_{3}\right]$ complexes $\left(\mathrm{D}_{2} \mathrm{O}, \mathrm{pD}=4.5,346 \mathrm{~K}\right)$ for (a) $i={ }^{17} \mathrm{O}$ of hydroxyl group, and (b) $i={ }^{1} \mathrm{H}$ of methylene group, while $k={ }^{13} \mathrm{C}$ of carboxylate group in both cases.
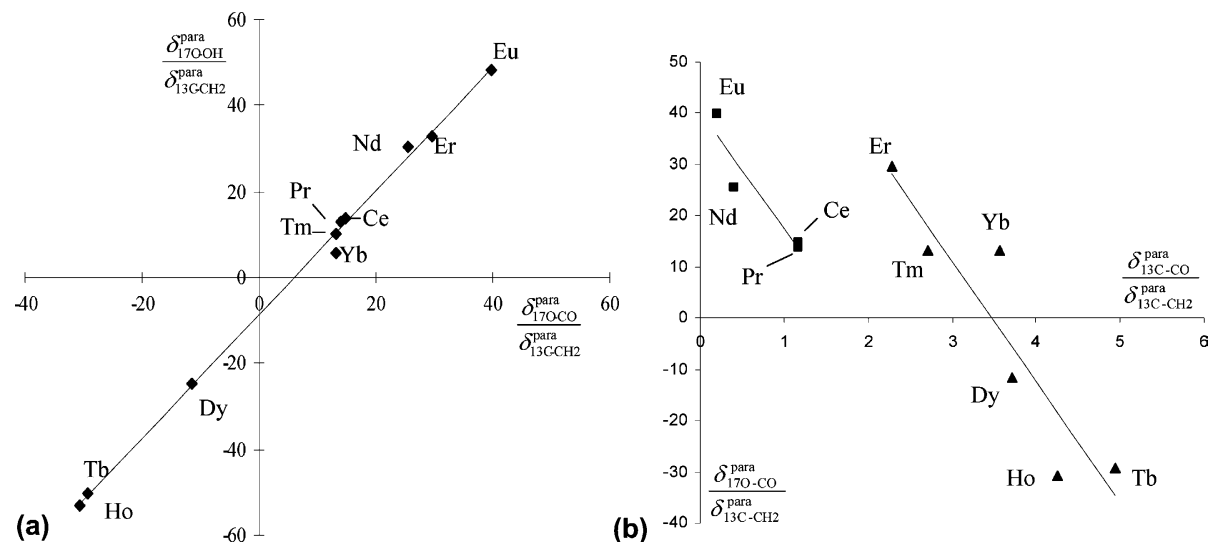

Fig. 4. Shift ratio plots of (a) $\delta\left({ }^{17} \mathrm{O}-\mathrm{OH}\right) / \delta\left({ }^{13} \mathrm{C}-\mathrm{CH}_{2}\right)$ vs. $\delta\left({ }^{17} \mathrm{O}-\mathrm{CO}\right) / \delta\left({ }^{13} \mathrm{C}-\mathrm{CH}_{2}\right)$, and $(\mathrm{b}) \delta\left({ }^{17} \mathrm{O}-\mathrm{Co}\right) / \delta\left({ }^{13} \mathrm{C}-\mathrm{CH}_{2}\right)$ vs. $\delta\left({ }^{13} \mathrm{C}-\mathrm{CO}\right) / \delta\left({ }^{13} \mathrm{C}-\mathrm{CH} 2\right)$, for the series of $\left[\mathrm{Ln}(\mathrm{GLYC})_{3}\left(\mathrm{H}_{2} \mathrm{O}\right)_{3}\right]$ complexes $\left(\mathrm{D}_{2} \mathrm{O}, \mathrm{pD}=4.5,346 \mathrm{~K}\right)$. 
the solid-state crystal structures reported for $\mathrm{Na}_{3}$ $\left[\mathrm{Ln}(\mathrm{ODA})_{3}\right] \cdot 2 \mathrm{NaClO}_{4} \cdot 6 \mathrm{H}_{2} \mathrm{O}(\mathrm{Ln}=\mathrm{La}-\mathrm{Lu})$, where the $\mathrm{Ln}$ (III) is co-ordinated by nine oxygen donors in pseudo-tricapped trigonal prismatic arrangements [38]. A dynamic intramolecular interconversion between the two helical enantiomers $P$ - $\left[\operatorname{Ln}(\mathrm{ODA})_{3}\right]^{3-} \rightleftharpoons M$ - $[\mathrm{Ln}$ $\left.(\mathrm{ODA})_{3}\right]^{3-}$ is present in solution, as shown by the observation of two resolved signals for the methylene protons for the heavy lanthanides $\mathrm{Ln}=\mathrm{Ho}-\mathrm{Yb}$, reflecting the larger pseudo-contact contributions induced in the second part of the lanthanide series and a slower exchange rate due to stronger lanthanide-ligand bonds. Plots according to Eqs. (2) and (3) along the lanthanide series for $\left[\operatorname{Ln}(\mathrm{ODA})_{3}\right]^{3-}$ have been obtained [37]. While the later plots show scattered data, the earlier ones show two unambiguous linear correlations, with an abrupt break occurring near the middle of the series $(\mathrm{Eu}-\mathrm{Tb})$, indicating variations of the contact $F_{i}$ and pseudo-contact $B_{0}^{2} G_{i}$ terms (Fig. 5). This was ascribed to a structural change involving nine-co-ordinate $D_{3}$-symmetrical $\left[\operatorname{Ln}(\mathrm{ODA})_{3}\right]^{3-}$ complexes similar to those found in the crystal structure for $\mathrm{Ln}=\mathrm{Ce}-\mathrm{Eu}$, and eight-co-ordinate complexes with low symmetry for $\mathrm{Ln}=\mathrm{Tb}-\mathrm{Yb}$, with fast on-off equilibria of the non-co-ordinated carboxylate group [37]. However, these conclusions are in strong contrast with the solid-state structures of the complexes, which show similar nine-co-ordinate $\mathrm{Ln}(\mathrm{III})$ ions along the complete lanthanide series [38]. Detailed spectroscopic investigations performed on these crystals have shown that some of their crystal-field parameters $B_{q}^{k}$ undergo an abrupt variation near the middle of the series [38], which is expected to produce a break in the linear plots according to Eq. (2) without resorting to a major structural change. This matter was further investigated through data analysis [37] using the crystalfield independent two-nuclei technique (Eq. (4)). A plot

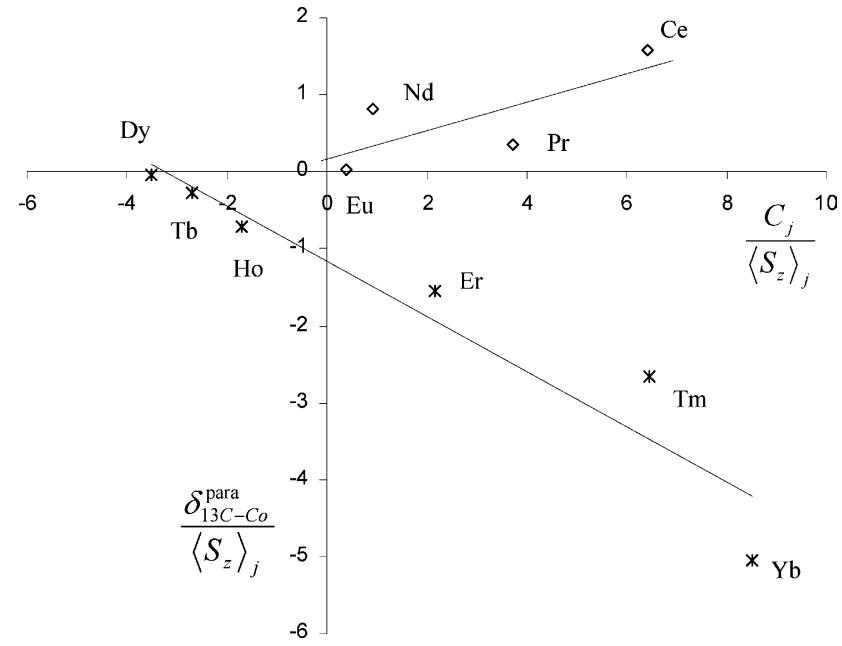

Fig. 5. Plot of $\delta_{i j}^{\text {para }} /\left\langle S_{z}\right\rangle_{j}$ vs. $C_{j} /\left\langle S_{z}\right\rangle_{j}$ along the lanthanide series of $\left[\mathrm{Ln}(\mathrm{ODA})_{3}\right]^{3-}$ complexes $\left(\mathrm{D}_{2} \mathrm{O}, 346 \mathrm{~K}\right)$ for the carboxylate ${ }^{13} \mathrm{C} \mathrm{nu}-$ cleus.

of $\delta_{i j}^{\text {para }} /\left\langle S_{z}\right\rangle_{j}$ versus $\delta_{k j}^{\text {para }} /\left\langle S_{z}\right\rangle_{j}$ for $j=\mathrm{Ce}-\mathrm{Yb}$ is approximately linear for $i=\mathrm{CH}_{2}$ and $k=\mathrm{CH}_{2}$ (Fig. 6a), which is compatible with an approximate isostructural series in solution. However, the same plots for $i=\mathrm{CH}_{2}$ and $k=C_{\mathrm{o}}$, and $i=\mathrm{CH}_{2}$ and $k=C_{\mathrm{o}}$ (Fig. 6b) are not linear, displaying two different, non-parallel straight lines, where the $\mathrm{Ln}=\mathrm{Nd}-\mathrm{Dy}$ data are clearly separate from the other lanthanide data. Thus, two different sets of $R_{i k}$ and $F_{i}$ values are obtained, confirming a structural change along the series of complexes. This structural change, together with a change of the crystal field parameter $B_{0}^{2}$, justifies the observed changes of $F_{i}$ and $B_{0}^{2} G_{i}$.

A plot of $\delta_{i j}^{\text {para }} / \delta_{k j}^{\text {para }}$ versus $\delta_{l j}^{\text {para }} / \delta_{k j}^{\text {para }}$ according to the three-nuclei method (Eq. (5)), where $i=\mathrm{CH}_{2}, k=$ $\mathrm{CH}_{2}$ and $l=C_{\mathbf{0}}$ (Fig. 7) confirms the structural break occurring near the middle of the series. Two approxi-

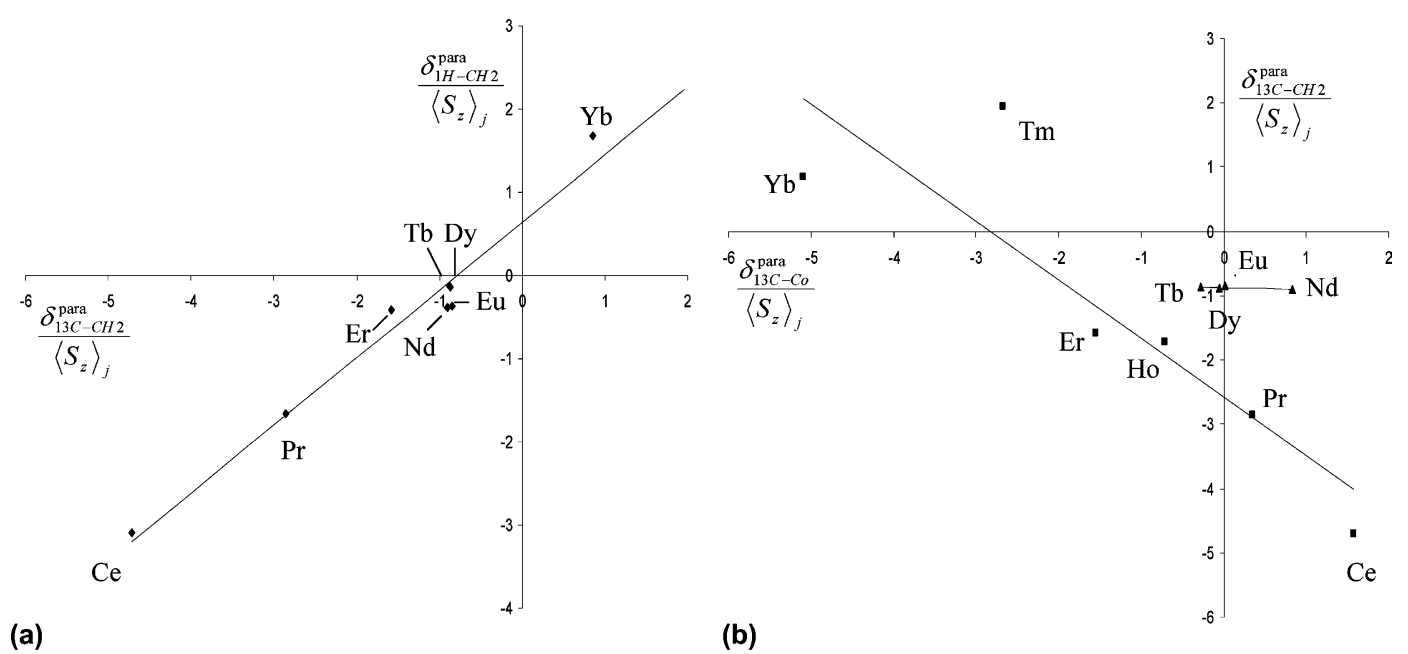

Fig. 6. Plots of $\delta_{i j}^{\text {para }} /\left\langle S_{z}\right\rangle_{j}$ vs. $\delta_{k j}^{\text {para }} /\left\langle S_{z}\right\rangle_{j}$ along the series of $\left[\mathrm{Ln}(\mathrm{ODA})_{3}\right]^{3-}$ complexes $\left(\mathrm{D}_{2} \mathrm{O}, 346 \mathrm{~K}\right)$ for: (a) $i={ }^{1} \mathrm{H}$ and $k={ }^{13} \mathrm{C}$ of methylene group, (b) $i={ }^{13} \mathrm{C}$ of methylene group and $k={ }^{13} \mathrm{C}$ of carboxylate group. 


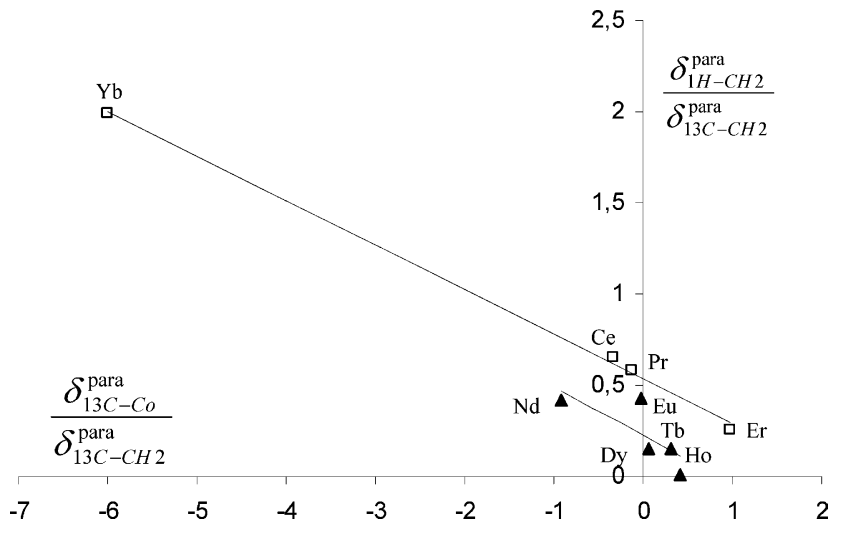

Fig. 7. Shift ratio plot of $\delta\left({ }^{1} \mathrm{H}-\mathrm{CH}_{2}\right) / \delta\left({ }^{13} \mathrm{C}-\mathrm{CH}_{2}\right)$ vs. $\delta\left({ }^{13} \mathrm{C}-\mathrm{CO}\right) /$ $\delta\left({ }^{13} \mathrm{C}-\mathrm{CH}_{2}\right)$ for the series of $\left.\left[\mathrm{Ln}(\mathrm{ODA})_{3}\right]\right]^{3-}$ complexes $\left(\mathrm{D}_{2} \mathrm{O}, 346 \mathrm{~K}\right)$.

mately parallell lines are obtained (one for $\mathrm{Ln}=\mathrm{Nd}-\mathrm{Tb}$ and the other for $\mathrm{Ln}=\mathrm{Ce}, \mathrm{Pr}, \mathrm{Er}, \mathrm{Yb}$ ) with nearly the same slope $\alpha$ and different intercepts $\beta$, which depend on $F_{i}$ and $G_{i}$ parameters.

\section{3. $\left[\operatorname{Ln}(P D C A)_{3}\right]^{3-} \quad\left(L^{3}=2,6-\right.$ pyridinedicarboxylic acid, $P D C A$ )}

The observed ${ }^{1} \mathrm{H}$ and ${ }^{13} \mathrm{C}$ NMR data for the [Ln $\left.(\mathrm{PDCA})_{3}\right]^{3-}$ complexes confirmed the formation of $D_{3}$ symmetrical triple-helical complexes in $\mathrm{D}_{2} \mathrm{O}$ solution [19], in agreement with the solid-state crystal structures reported for $\mathrm{M}_{3}\left[\mathrm{Ln}(\mathrm{PDCA})_{3}\right]$ along the complete lanthanide series, which show the $\operatorname{Ln}(\mathrm{III})$ in pseudotricapped trigonal prismatic sites, six oxygen atoms of the carboxylate groups occupying the vertices of the trigonal prism and the three nitrogen atoms of the pyridine rings capping the rectangular faces $[39,40]$. Plots of the ${ }^{1} \mathrm{H}$ and ${ }^{13} \mathrm{C}$ paramagnetic shifts $\delta_{i j}^{\text {para }}$, obtained for the $\left[\operatorname{Ln}(\mathrm{PDCA})_{3}\right]^{3-}$ complexes $(\mathrm{Ln}=\mathrm{Pr}, \mathrm{Eu}$, $\mathrm{Tb}-\mathrm{Yb}$ ), according to Eqs. (2) and (3) [19] suggested linear behaviours compatible with isostructurality (i.e. invariance of $G_{i}$ ) and invariance of $F_{i}$ and $B_{0}^{2}$ along the complete lanthanide series. Moreover, least-squares fits of the molecular structure based on $G_{i}$ calculated for the crystal structures of $\mathrm{M}_{3}\left[\operatorname{Ln}(\mathrm{PDCA})_{3}\right]$ showed only minor variations between solid-state and solution structures. However, in this early study only two members of the first part of the lanthanide series were considered $(\mathrm{Ln}=\mathrm{Pr}, \mathrm{Eu})$, strongly limiting the detection of any breaks between light and heavy lanthanides according to Eqs. (2) and (3). Moreover, these reports contrast with the significant variations of the ratio of pseudo-contact contributions $\delta_{\mathrm{H} 2 j}^{\mathrm{pc}} / \delta_{\mathrm{H} 3 j}^{\mathrm{pc}}$ found between light and heavy lanthanides for $\left[\operatorname{Ln}(\mathrm{PDCA})_{n}\right]^{(3-2 n)+}(n=1-3)$ [41].

The strict isostructurality combined with the invariance of $B_{0}^{2}$ proposed for the $\left[\operatorname{Ln}(\mathrm{PDCA})_{3}\right]^{3-}$ complexes in these early studies [19,42], were recently re-examined [30]. A new complete set of ${ }^{1} \mathrm{H}$ and ${ }^{13} \mathrm{C}$ NMR data for the $\left.\left[\operatorname{Ln}(\mathrm{PDCA})_{3}\right]^{3-}\right)$ complexes $(\mathrm{Ln}=\mathrm{Ce}-\mathrm{Yb}$, except $\mathrm{Pm}$,
$\mathrm{Gd}, 298 \mathrm{~K}, \mathrm{pD}=6.0)$ has been collected and analyzed with Eqs. (2)-(4). Plots of ${ }^{1} \mathrm{H}$ and ${ }^{13} \mathrm{C}$ NMR data of $\left[\mathrm{Ln}(\mathrm{PDCA})_{3}\right]^{3-}(\mathrm{R}=\mathrm{Ce}-\mathrm{Yb}$, except $\mathrm{Pm}, \mathrm{Gd})$ using Eqs. (2) and (3) show, in contrast with the original study [19], an abrupt break near the middle of the lanthanide series, attributed to variations of the contact $F_{i}$ and pseudocontact $B_{0}^{2} G_{i}$ terms [30]. Plots according to Eq. (4) systematically display two different, non-parallel straight lines for $\mathrm{Ln}=\mathrm{Ce}-\mathrm{Eu}$ and $\mathrm{Ln}=\mathrm{Tb}-\mathrm{Yb}$ [29], in line with previous observations [41]. Two different isostructural series are thus observed and the $R_{i k}$ terms calculated from the crystal structures of $\left[\operatorname{Ln}(\mathrm{PDCA})_{3}\right]^{3-}(\mathrm{Ln}=\mathrm{La}, \mathrm{Lu})$ [40] compare well with those found in solution for $\mathrm{Ln}=\mathrm{Tb}-\mathrm{Yb}$, but not for $\mathrm{Ln}=\mathrm{Ce}-\mathrm{Eu}$ [30]. Molecular modeling has shown that the latter $R_{i k}$ terms result from oscillations of the central pyridine rings displaying considerable amplitude for light $\mathrm{Ln}(\mathrm{III})$. For $\mathrm{Ln}=\mathrm{Tb}-\mathrm{Yb}$, the stronger $\left(\mathrm{R}-\mathrm{N}_{\text {pyridine }}\right.$ bonds limit those oscillations and only minor displacements from the equilibrium position could be detected. Although related distorsions are not observed in the crystal structures for $\left[\operatorname{Ln}(\operatorname{PDCA})_{3}\right]^{3-}$ $(\mathrm{Ln}=\mathrm{La}, \mathrm{Lu})$, large torsions of the pyridine rings are exemplified in the crystal structure of the analogous complex $\left[\mathrm{La}\left(\mathrm{L}^{4}\right)_{3}\right]^{3+}[43]$. The existence of a structural change (oscillation of the pyridine rings) between $\mathrm{Ln}=\mathrm{Eu}$ and $\mathrm{Ln}=\mathrm{Tb}$ for $\left[\operatorname{Ln}(\mathrm{PDCA})_{3}\right]^{3-}$, established by Eq. (4), originates the observed $F_{i}$ and $B_{0}^{2} G_{i}$ changes.

Finally, plots according to the three-nuclei method (Eq. (5)) confirm the abrupt break occurring near the middle of the series [30]. The experimental slopes $\alpha$ and intercepts $\beta$, which depend on $F_{i}$ and $G_{i}$ parameters, could be satisfactorily predicted from $F_{i}$ terms obtained with Eqs. (2) and (3) and $G_{i}$ terms resulting from the combination of structural modeling and Eq. (4) [30].

Compared to the original report [19] proposing the invariance of $G_{i}, F_{i}$ and $B_{0}^{2}$ along the complete lanthanide series, the recent re-examination of the new complete set of NMR data [30] reaches opposite conclusions and establishes a change of $G_{i}, F_{i}$ and $B_{0}^{2}$ between $\mathrm{Ln}=\mathrm{Eu}$ and $\mathrm{Ln}=\mathrm{Tb}$. This discrepancy results from the too limited set of data collected in the early study for the light lanthanides and by fortuitous compensation effects produced by the variations of $G_{i}$ and $B_{0}^{2}$ for $\mathrm{H}_{2}, \mathrm{H}_{3}$ and $\mathrm{C}_{3}$, providing invariant pseudo-contact terms $B_{0}^{2} G_{i}$ along the complete series for these nuclei.

\section{4. $\left[\operatorname{Ln}\left(L^{4}\right)_{3}\right]^{3+} \quad\left(L^{4}=2,6\right.$-pyridinedicarboxylic acid- bis-diethylamide)}

The two neutral carboxamide substituent groups in the pyridine ring provide a tridentate $\mathrm{NO}_{2}$ chelate which exhibits significant affinity for $\operatorname{Ln}(\mathrm{III})$ in acetonitrile [43], in which the triple helical complexes $\left[\mathrm{Ln}\left(\mathrm{L}^{4}\right)_{3}\right]^{3+}$ are quantitatively formed at a total ligand concentration of $0.15 \mathrm{M}$ and $\mathrm{Ln} / \mathrm{L}^{4}=0.33$. The ${ }^{1} \mathrm{H}$ and ${ }^{13} \mathrm{C}$ NMR data imply the existence of three equivalent ligand strands on 
the NMR time scale and the separated ${ }^{1} \mathrm{H}$ NMR signals detected for the methylene protons of the ethyl groups of the carboxamide side arms $(\mathrm{Ln}=\mathrm{Y}, \mathrm{Lu})$ points to the formation of $D_{3}$-symmetrical complexes in solution reminiscent of the crystal structures obtained for $\left[\mathrm{Ln}\left(\mathrm{L}^{4}\right)_{3}\right]^{3+}(\mathrm{Ln}=\mathrm{La}$, Eu $)$ [43]. Variable-temperature NMR measurements for $\left[\operatorname{Ln}\left(\mathrm{L}^{4}\right)_{3}\right]^{3+}(\mathrm{Ln}=\mathrm{La}, \mathrm{Sm}, \mathrm{Y}$, $\mathrm{Lu})$ in acetonitrile firmly establish the dynamic interconversion between the $D_{3}$-symmetrical helical enantiomers $P$ - $\left[\operatorname{Ln}\left(\mathrm{L}^{4}\right)_{3}\right]^{3+} \rightleftharpoons M$ - $\left[\operatorname{Ln}\left(\mathrm{L}^{4}\right)_{3}\right]^{3+}$.

Plots of ${ }^{1} \mathrm{H}$ and ${ }^{13} \mathrm{C}$ NMR data of $\left[\mathrm{Ln}\left(\mathrm{L}^{4}\right)_{3}\right]^{3+}$ $(\mathrm{Ln}=\mathrm{Ce}-\mathrm{Yb}$, except Pm, Gd, Dy, Ho) at $298 \mathrm{~K}$ in $\mathrm{CD}_{3} \mathrm{CN}$, according to Eqs. (2) and (3) display abrupt deviations from linearity between $\mathrm{Tb}$ and $\mathrm{Er}$ [43]. Two different isostructural series were considered for $\mathrm{Ln}=\mathrm{Ce}-$ $\mathrm{Tb}$ and $\mathrm{Er}-\mathrm{Yb}$, and two sets of contact $F_{i}$ and pseudocontact $B_{0}^{2} G_{i}$ terms were obtained from least-squares fits of Eq. (2) [43]. The crystal field independent method was also applied to unambiguously demonstrate that a structural change occurs along the lanthanide series $[31,44]$. Plots according to Eq. (4) indeed display systematic abrupt breaks between $\mathrm{Tb}$ and $\mathrm{Er}$, leading to two different sets of structural terms $R_{i k}=G_{i} / G_{k}[31,44]$. A comparison of these experimental $R_{i k}$ values with those calculated for the $D_{3}$-averaged X-ray crystal structure of $\left[\mathrm{Eu}\left(\mathrm{L}^{4}\right)_{3}\right]\left(\mathrm{CF}_{3} \mathrm{SO}_{3}\right)_{3}$ shows that this crystal structure is a better model of the solution structure of the $\left[\mathrm{Ln}\left(\mathrm{L}^{4}\right)_{3}\right]^{3+}$ complexes with the larger $\mathrm{Ln}^{3+}$ ions $(\mathrm{Ce}-\mathrm{Tb})$ than for the smaller ones [31]. Finally, relaxation measurements and Eq. (6) were used to extract $\mathrm{Ln}-\mathrm{H}_{i}$ and $\mathrm{Ln}-\mathrm{C}_{i}$ distances, which indeed slightly differ for $\mathrm{Ln}=\mathrm{Ce}$ and $\mathrm{Yb}$ [43]. A structural change was thus firmly established for $\left[\operatorname{Ln}\left(\mathrm{L}^{4}\right)_{3}\right]^{3+}$ near the middle of the lanthanide series $[31,43]$. Its assignment to specific variations of structural parameters was also ascribed to fast oscillations of the central pyridine ring occurring for the large $\mathrm{Ln}^{3+}$ ions, $\mathrm{Ln}=\mathrm{Ce}-\mathrm{Tb}$, while the structure of the complexes with the smaller large $\mathrm{Ln}^{3+}$ ions becomes more compact, with a slight flattening along the $C_{3}$-axis, a process similar to that detected in $\left[\operatorname{Ln}(\mathrm{PDCA})_{3}\right]^{3-}$ complexes [30].

\section{5. $\left[\operatorname{Ln}(B B Z P)_{3}\right]^{3+}\left(L^{5}=2,6-b i s\right.$ (benzimidazole) pyri- dine, $B B Z P)$}

Due to the limited affinity of the heterocyclic nitrogen donors in the tridentate ligand $\mathrm{L}^{5}$ for $\mathrm{Ln}(\mathrm{III})$, no complexation occurs in water, but formation of [ $\mathrm{Ln}$ $\left.(\mathrm{BBZP})_{n}\right]^{3+}(n=1-3)$ complexes occurs in acetonitrile [45]. The $\left[\operatorname{Ln}(\mathrm{BBZP})_{3}\right]^{3+}$ complexes are quantitatively formed for $\mathrm{Ln}=\mathrm{Ce}-\mathrm{Dy}$, but are less stable for the smaller lanthanides, where partial decomplexation occurs [46]. The ${ }^{1} \mathrm{H}$ and ${ }^{13} \mathrm{C}$ NMR data are in agreement with threefold symmetry of the complexes, the expected helical wrapping of the strands giving an average $D_{3}$ point group symmetry in solution. Plots for $\left[\mathrm{Ln}(\mathrm{BBZP})_{3}\right]^{3+}(\mathrm{Ln}=\mathrm{Ce}-\mathrm{Dy})$ using Eqs. (2) and (3) give linear correlations arising from a single isostructural series, with constant $F_{i}$ and $B_{0}^{2} G_{i}$ values [46]. Using the crystal-field independent two-nuclei technique, plots using Eq. (4) give a single straight line for $\mathrm{Ln}=\mathrm{Ce}-\mathrm{Dy}$, thus confirming the isostructurality of the Ce-Dy complexes [44]. We further analysed the published data using the three-nuclei method using Eq. (5), with mixed results. Plots of ${ }^{1} \mathrm{H}$ shift ratios, $\delta\left(\mathrm{H}_{i}\right) / \delta\left(\mathrm{H}_{1}\right)$ versus $\delta\left(\mathrm{H}_{2}\right) /$ $\delta\left(\mathrm{H}_{1}\right)$ were linear for $i=\mathrm{H}_{3}$ and $\mathrm{CH}_{3}$, but for $i=\mathrm{H}_{4}, \mathrm{H}_{5}$ and $\mathrm{H}_{6}$, those plots were practically linear with the data for $\mathrm{Tb}$ and Dy clearly outside the lines defined by $\mathrm{Ce}-\mathrm{Eu}$ (Fig. 8a). The plots of ${ }^{13} \mathrm{C}$ shift ratios, $\delta\left(\mathrm{C}_{i}\right) / \delta\left(\mathrm{C}_{1}\right)$ versus $\delta\left(\mathrm{C}_{2}\right) / \delta\left(\mathrm{C}_{1}\right)$ were linear for $i=\mathrm{C}_{3}, \mathrm{C}_{4}, \mathrm{C}_{5}$ and $C_{3}$, but not for $\mathrm{C}_{6}$ (Fig. 8b). Although the $\alpha$ and $\beta$ parameters of such linear correlations depend on the $F_{i}$ and $G_{i}$ parameters in a complicated but very sensitive manner (as described before), the lack of linearity of some of the above plots may indicate that a structural change is occurring at $\mathrm{Eu}-\mathrm{Tb}$, which is unnoticed by the plots according to Eq. (4). Some of the nuclei are more

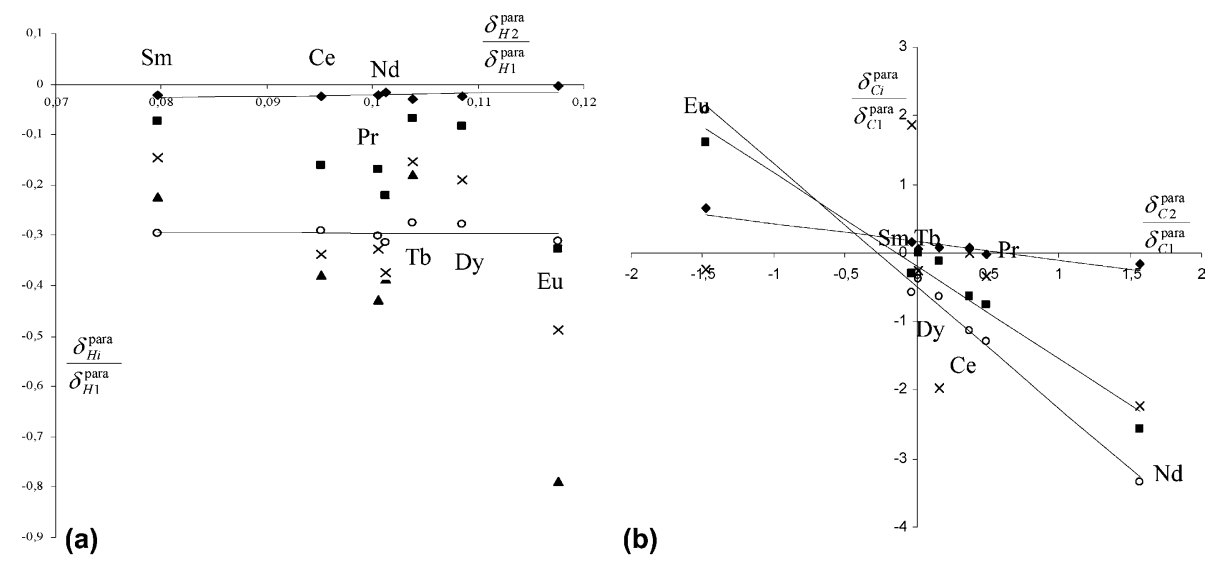

Fig. 8. Shift ratio plots (a) for ${ }^{1} \mathrm{H}$ shifts, $\delta\left(\mathrm{H}_{i}\right) / \delta\left(\mathrm{H}_{1}\right)$ vs. $\delta\left(\mathrm{H}_{2}\right) / \delta\left(\mathrm{H}_{1}\right)\left(i=\mathrm{H}_{3}(\bullet), \mathrm{H}_{4}(\boldsymbol{\square}), \mathrm{H}_{5}(\boldsymbol{\Delta}), \mathrm{H}_{6}(\times)\right.$ and $\left.\mathrm{C} H_{3}(\mathrm{O})\right)$, and $(\mathrm{b})$ for ${ }^{13} \mathrm{C}$ shifts, $\delta\left(\mathrm{C}_{i}\right) /$ $\delta\left(\mathrm{C}_{1}\right)$ vs. $\delta\left(\mathrm{C}_{2}\right) / \delta\left(\mathrm{C}_{1}\right)\left(\mathrm{i}=\mathrm{C}_{3}(\bullet), \mathrm{C}_{4}(\mathbf{\square}), \mathrm{C}_{6}(\times)\right.$ and $\left.\mathrm{CH}_{3}(\mathrm{O})\right)$ of the $\left[\mathrm{Ln}(\mathrm{BBZP})_{3}\right]^{3+}$ complexes. 
sensitive than others to such a structural change using the three-nuclei method.

In any case, the $\left[\operatorname{Ln}(\mathrm{BBZP})_{3}\right]^{3+}(\mathrm{Ln}=\mathrm{Ce}-\mathrm{Eu})$ complexes are isostructural in solution and adopt a structure reminiscent to that found in the crystal structure of $\left[\mathrm{Eu}\left(\mathrm{L}^{2}\right)_{3}\right]^{3+}$. A structural change may occur in the second half of the lanthanide series, but the unavailability of NMR data for the lanthanide complexes after Dy makes any firm conclusion rather difficult.

\section{6. $\operatorname{Ln}(\text { terpy })_{3}\left(\mathrm{CF}_{3} \mathrm{SO}_{3}\right)_{3}\left(\mathrm{~L}^{6}=\right.$ terpyridine, terpy $)$}

${ }^{1} \mathrm{H}$ and ${ }^{13} \mathrm{C}$ LIS data have been reported for a series of $\mathrm{Ln}(\text { terpy })_{3}\left(\mathrm{CF}_{3} \mathrm{SO}_{3}\right)_{3}(\mathrm{Ln}=\mathrm{Pr}, \mathrm{Nd}, \mathrm{Eu}, \mathrm{Tb}, \mathrm{Dy}, \mathrm{Ho}$, Er, Tm, $\mathrm{Yb}$ ) complexes at $298 \mathrm{~K}$ in $\mathrm{CD}_{3} \mathrm{CN}$ [47]. Analysis of the data using the program SHIFT ANALYSIS [48] showed that the $\operatorname{Ln}(\text { terpy })_{3}\left(\mathrm{CF}_{3} \mathrm{SO}_{3}\right)_{3}$ complexes are isostructural in solution and can be described by a tricapped trigonal prismatic configuration [47]. As shown in Fig. 9, ${ }^{1} \mathrm{H}$ LIS data of the $\mathrm{Ln}$ (terpy $)_{3}\left(\mathrm{CF}_{3} \mathrm{SO}_{3}\right)_{3}$ complexes, when plotted according to Eq. (5) in the form of $\delta_{i j}^{\text {para }} / \delta_{k j}^{\text {para }}$ versus $\delta_{l j}^{\text {para }} / \delta_{k j}^{\text {para }}$ $\left(i=\mathrm{H}_{3}, \mathrm{H}_{5}, \mathrm{H}_{6} ; k=\mathrm{H}_{4} ; j=\mathrm{H}_{1}\right)$, show very good linearity, thus supporting the conclusions of isostructurality of the complexes. Table 1 summarizes the $\alpha$ and $\beta$ values

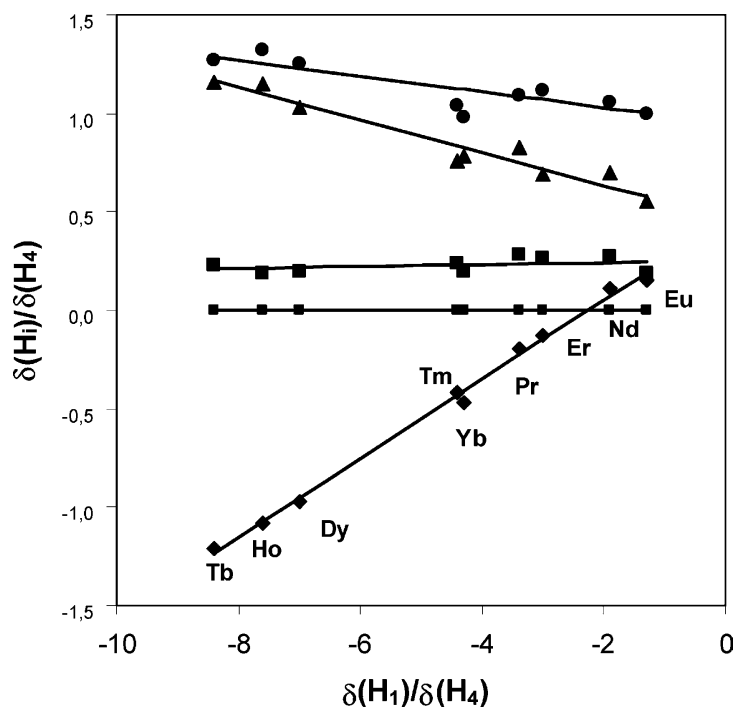

Fig. 9. ${ }^{1} \mathrm{H}$ shift ratio plots of $\delta\left(\mathrm{H}_{i}\right) / \delta\left(\mathrm{H}_{4}\right)$ vs. $\delta\left(\mathrm{H}_{1}\right) / \delta\left(\mathrm{H}_{4}\right)\left(i=\mathrm{H}_{2}(\bullet)\right.$, $\mathrm{H}_{3}(\boldsymbol{\square}), \mathrm{H}_{5}(\boldsymbol{\Delta})$, and $\left.\mathrm{H}_{6}(\bullet)\right)$ for the $\mathrm{Ln}(\text { terpy })_{3}\left(\mathrm{CF}_{3} \mathrm{SO}_{3}\right)_{3}$ complexes.

Table 1

$\alpha$ and $\beta$ values calculated in the plots of $\delta_{i j}^{\text {para }} / \delta_{k j}^{\text {para }}$ vs. $\delta_{l j}^{\text {para }} / \delta_{k j}^{\text {para }}$ ( $i=\mathrm{H}_{2}, \mathrm{H}_{3}, \mathrm{H}_{5}$ and $\mathrm{H}_{6}, k=\mathrm{H}_{4}, l=H_{1}$ ) according to Eq. (5) for the ${ }^{1} \mathrm{H}$ NMR shift data of the $\mathrm{Ln}($ Terpy $)\left(\mathrm{CF}_{3} \mathrm{SO}_{3}\right)_{3}$ complexes

\begin{tabular}{llll}
\hline$H_{i}$ & $\alpha$ & $\beta$ & $R^{2}$ \\
\hline 2 & 0.196 & 0.441 & 0.995 \\
3 & 0.005 & 0.251 & 0.171 \\
5 & -0.075 & 0.462 & 0.939 \\
6 & -0.043 & 0.889 & 0.778 \\
\hline
\end{tabular}

obtained from the ${ }^{1} \mathrm{H}$ LIS data of the $\operatorname{Ln}(\text { terpy })_{3}$ $\left(\mathrm{CF}_{3} \mathrm{SO}_{3}\right)_{3}$ complexes from these plots. A small slope $(\alpha=0.005)$ was found for $i=\mathrm{H}_{3}$, indicating that $F\left(H_{3}\right) / F\left(H_{4}\right) \approx G\left(H_{3}\right) / G\left(H_{4}\right)$ in these complexes.

2.7. $\left.\left[\mathrm{LnZnL}^{7}\right)_{3}\right]^{5+}$ and $\left[\mathrm{LnCo}\left(\mathrm{L}^{7}\right)_{3}\right]^{5 / 6+}\left(L^{7}=2-\{6-\right.$ $[N, N$-diethylcarboxamido]-pyridin-2-yl\}-1,1'-dimethyl-5, 5'-methylene-2'-(5-methylpyridin-2-yl) bis [1 H-benzimidazole])

The segmental ligand $\mathrm{L}^{7}$ possesses a $\mathrm{NN}$ bidentate binding unit adapted for co-ordination of d-block ions and an unsymmetrical NNO tridentate binding unit for the co-ordination of $4 \mathrm{f}$-block ions [49]. It quantitatively forms $C_{3}$-symmetrical triple-stranded helicates $(\mathrm{HHH})$ $\left[\mathrm{LnZn}\left(\mathrm{L}^{7}\right)_{3}\right]^{5+}$ in acetonitrile, where the $\left(\mathrm{Zn}^{2+}\right.$ is pseudooctahedrally six-co-ordinated by the three bidentate binding units and the $\mathrm{Ln}^{3+}$ is nine-coordinated by the three tridentate units in a pseudo-tricapped trigonal prismatic geometry. As the $\operatorname{Ln}$ (III) is the only source of paramagnetism, the ${ }^{1} \mathrm{H}$ LIS data $(\mathrm{Ln}=\mathrm{La}, \mathrm{Ce}, \mathrm{Pr}, \mathrm{Nd}$, $\mathrm{Sm}, \mathrm{Eu}, \mathrm{Tm}, \mathrm{Yb}, \mathrm{Lu}$ ) in acetonitrile solution were analyzed with the usual model-free methods [50]. Although plots according to Eqs. (2) and (3) suggested that $\mathrm{Ln}=\mathrm{Tm}, \mathrm{Yb}$ do not belong to the straight line found for $\mathrm{Ln}=\mathrm{Ce}-\mathrm{Eu}$, multi-linear least-squares fits of Eq. (2) considering a single isostructural series $(\mathrm{Ln}=\mathrm{Ce}-\mathrm{Yb})$ have been applied for the separation of contact and pseudo-contact contributions and to obtain $F_{i}$ and $B_{0}^{2} G_{i}$ terms, giving poor agreement factors [50]. However, it was concluded that the crystal structure of [Eu$\left.\mathrm{Zn}\left(\mathrm{L}^{7}\right)_{3}\right]^{5+}$ is a satisfying structural model for the complete lanthanide series.

In order to design highly rigid helicates displaying a single isostructural series of complexes in solution, the kinetically inert diamagnetic $\mathrm{Co}(\mathrm{III})$ ( $\mathrm{d}^{6}$ low spin) was introduced into the non-covalent tripod [51]. The complexes are stable in acetonitrile and almost identical crystal structures were obtained for lanthanide ions of extreme sizes $(\mathrm{HHH})-\left[\mathrm{LnCo}\left(\mathrm{L}^{7}\right)_{3}\right]^{6+}(\mathrm{Ln}=\mathrm{La}, \mathrm{Lu})$, strongly suggesting that the considerable rigidity of the wrapped ligand strands minimizes any structural variations associated with the lanthanide contraction [31].

The ${ }^{1} \mathrm{H}$ NMR spectra of $(\mathrm{HHH})-\left[\operatorname{LnCo}\left(\mathrm{L}^{7}\right)_{3}\right]^{6+}$ ( $\mathrm{Ln}=\mathrm{La}-\mathrm{Lu}$, except $\mathrm{Pm}, \mathrm{Gd}$ ) confirm the quantitative formation of rigid $C_{3}$-symmetrical complexes in acetonitrile. Field-dependent $T_{1}$ and $T_{2}$ relaxation measurements for $(\mathrm{HHH})-\left[\mathrm{LnCo}\left(\mathrm{L}^{7}\right)_{3}\right]^{6+}(\mathrm{Ln}=\mathrm{Tb}, \mathrm{Tm})$ gave, through Eq. (6), $\mathrm{Ln}-\mathrm{H}_{i}$ distances very close to those found in the solid state, in agreement with negligible structural changes occurring along the lanthanide series in solution [31]. However, plots using crystal-field dependent techniques (Eqs. (2) and (3)) show systematic abrupt breaks near the middle of the lanthanide series (between $\mathrm{Ln}=\mathrm{Eu}$ and $\mathrm{Tb}$ ), which imply a change of the $F_{i}$ and $B_{0}^{2} G_{i}$ terms. The analyses of the data with the 
crystal-field independent technique display straight lines for plots following Eq. (4), in agreement with isostructurality along the lanthanide series and no significant change of the $G_{i}$ factors. Thus, since $G_{i}$ is essentially invariant, an abrupt variation of the crystalfield parameter $B_{0}^{2}$ was proposed in order to rationalize the NMR data. The observed change of $F_{i}$ had negligible effects on the intercept $\left(F_{i}-F_{k} R_{i k}\right)$ of linear plots obtained according to Eq. (4), although variations of $F_{i}$ terms are expected to produce two parallel straight lines in such plots, as demonstrated for the cryptates $\left[\operatorname{Ln}\left(\mathrm{L}^{8}\right)\right]^{3+}$ (see later) [26].

Reduction of Co(III) to Co(II) provides a second fastrelaxing paramagnetic centre $\left(\mathrm{Co}(\mathrm{II}), \mathrm{d}^{7}\right.$ high spin, $S=3 / 2$ ) within the triple-stranded helicates (HHH)$\left[\mathrm{LnCo}\left(\mathrm{L}^{7}\right)_{3}\right]^{5+}$ strongly affecting the ${ }^{1} \mathrm{H}$ NMR spectra. Since no intermetallic Ln-Co(II) magnetic coupling could be detected at $298 \mathrm{~K}$, the paramagnetic shifts induced by the two metallic centres were treated as additive [31]. Complete assignment of the ${ }^{1} \mathrm{H}$ NMR signals in strongly paramagnetic lanthanide-containing complexes, and detailed model-free analyses (Eqs. (2)-(4)) using the complex (HHH)-[ $\left[\mathrm{LaCo}^{\mathrm{II}}\left(\mathrm{L}_{7}\right)_{3}\right]^{5+}$ as the 'diamagnetic' reference, gave evidence of very similar structural properties for $(\mathrm{HHH})-\left[\mathrm{LnCo}^{\mathrm{II}}\left(\mathrm{L}^{7}\right)_{3}\right]^{5+}$ and $(\mathrm{HHH})-\left[\mathrm{LnCo}^{\mathrm{III}}\right.$ $\left.\left(\mathrm{L}^{7}\right)_{3}\right]^{6+}$. An abrupt change of $F_{i}$ and of the crystal-field parameter $B_{0}^{2}$ was observed between $\mathrm{Ln}=\mathrm{Eu}$ and $\mathrm{Tb}$ for $(\mathrm{HHH})-\left[\mathrm{LnCo}^{\mathrm{II}}\left(\mathrm{L}^{7}\right)_{3}\right]^{5+}[31]$. Thus, the conclusion that abrupt variations of the $F_{i}$ and $B_{2}^{0}$ parameters occur near the middle of the series, with no structural variations involved, for both $\left[\mathrm{LnCo}^{\mathrm{II}}\left(\mathrm{L}^{7}\right)_{3}\right]^{5+}$ and $\left[\mathrm{LnCo}^{\mathrm{III}}\left(\mathrm{L}^{7}\right)_{3}\right]^{6+}$ complexes, was only achieved by the two-nuclei crystalfield independent technique (Eq. (4)). The one-nucleus crystal-field dependent methods (Eqs. (2) and (3)) could not be used for detecting structural changes because the unpredictable abrupt variations of the crystal-field parameter $B_{0}^{2}$ along the lanthanide series masked that conclusion.

In the case of the $\left[\operatorname{LnCo}\left(\mathrm{L}^{7}\right)_{3}\right]^{5+}$ helicates, ${ }^{1} \mathrm{H}$ shift ratio plots, $\delta\left(\mathrm{H}_{i}\right) / \delta\left(\mathrm{H}_{9}\right)$ versus $\delta\left(\mathrm{H}_{6}\right) / \delta\left(\mathrm{H}_{9}\right)$, according to Eq. (5) (Fig. 10) give good linear correlations for all protons, reflecting the isostructural properties of this series of complexes. However, a closer analysis of the agreement factors ( $R^{2}$ values) for all the linear correlations, shows that those protons in Fig. 10a, concerning the protons $\mathrm{H}_{1}-\mathrm{H}_{5}, \mathrm{Me}_{1}$ and $\mathrm{Me}_{2}$, which are located close to the $\mathrm{Co}$ (II) binding site, and whose shifts are dominated by the Co(II) contribution, have higher $R^{2}$ values than most of the ones present in Fig. 10b, concerning the protons $\mathrm{H}_{10}-\mathrm{H}_{14}$ and $\mathrm{Me}_{3}-\mathrm{Me}_{5}$, which are located close to the $\mathrm{Ln}^{\mathrm{III}}$ binding site, whose shifts are dominated by the $\mathrm{Ln}$ (III) contribution. In particular, the $\mathrm{H}_{11}-\mathrm{H}_{14}$ nuclei have the largest deviations from linear correlations. This reflects the high sensitivity of the $\alpha$ and $\beta$ parameters of Eq. (5) of the later nuclei to a small, gradual structural change of the helicates along the
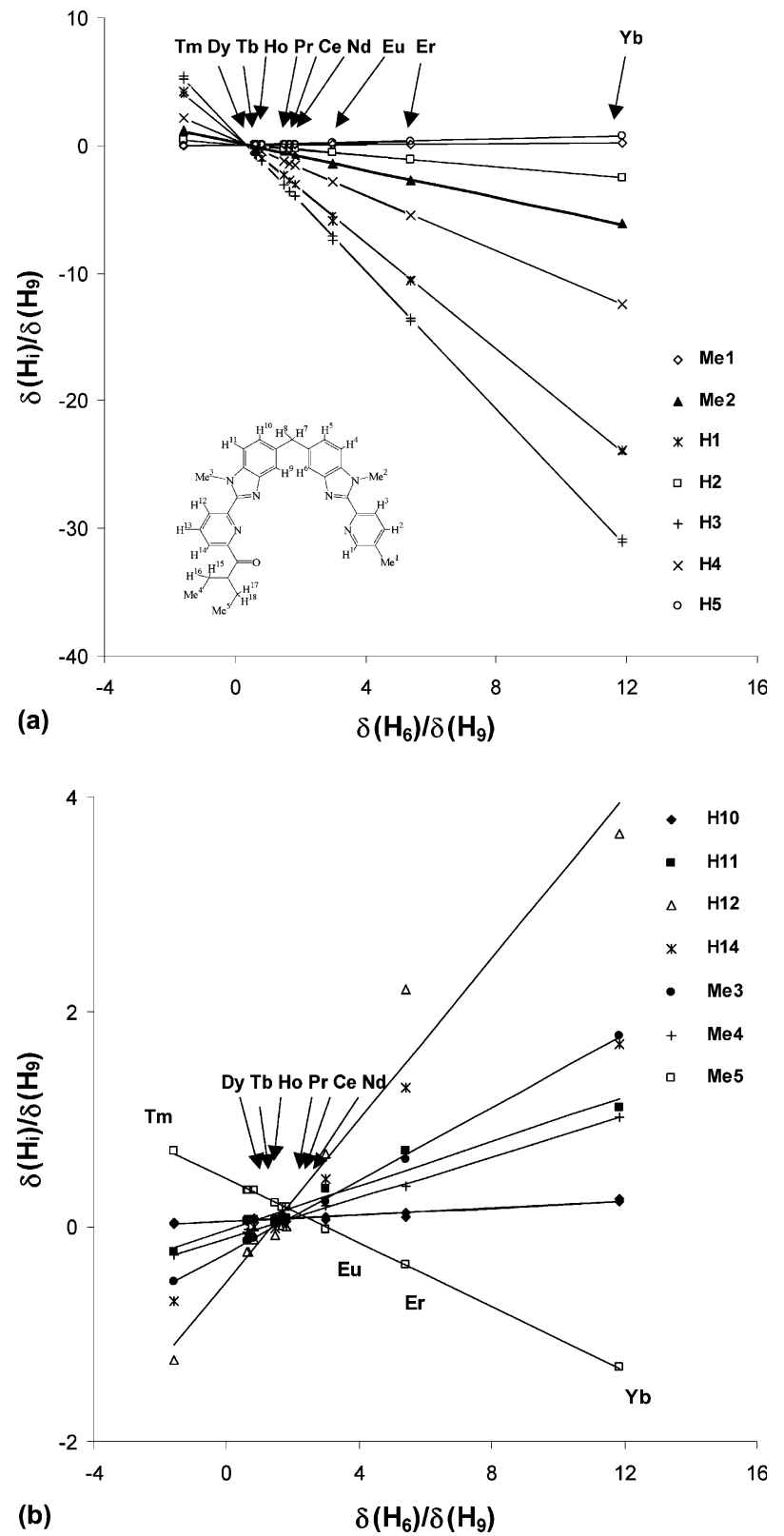

Fig. 10. ${ }^{1} \mathrm{H}$ shift ratio plots, $\delta\left(\mathrm{H}_{i}\right) / \delta\left(\mathrm{H}_{9}\right)$ vs. $\delta\left(\mathrm{H}_{6}\right) / \delta\left(\mathrm{H}_{9}\right)$ for the various protons of the $\left[\mathrm{LnCo}\left(\mathrm{L}^{7}\right)_{3}\right]^{5+}$ helicates: (a) protons close to the $\mathrm{Co}(\mathrm{II})$ site; (b) protons close to the $\operatorname{Ln}(\mathrm{III})$ site.

Ln(III) series. The graphical method based on Eq. (5) can report such a subtle process, with no need to separate out the paramagnetic effect of the $\mathrm{Co}(\mathrm{II})$ center.

In the case of the $\left[\mathrm{LnCo}\left(\mathrm{L}^{7}\right)_{3}\right]^{6+}$ helicates, the same ${ }^{1} \mathrm{H}$ shift ratio plots, $\delta\left(\mathrm{H}_{i}\right) / \delta\left(\mathrm{H}_{9}\right)$ versus $\delta\left(\mathrm{H}_{6}\right) / \delta\left(\mathrm{H}_{9}\right)$, according to Eq. (5) (Fig. 11) give very good linear correlations for most protons, except for $\mathrm{Me}_{5}$ and particularly, $\mathrm{H}_{14}, \mathrm{H}_{1}$ and $\mathrm{H}_{4}$. These nuclei seem to be the only ones sensitive to a small, gradual structural change of the oxidized helicates along the $\operatorname{Ln}$ (III) series, which seems to involve both metal sites, as some of these nuclei are close to the $\mathrm{Ln}$ (III) binding site and others close to the $\mathrm{Co}(\mathrm{II})$ site. 


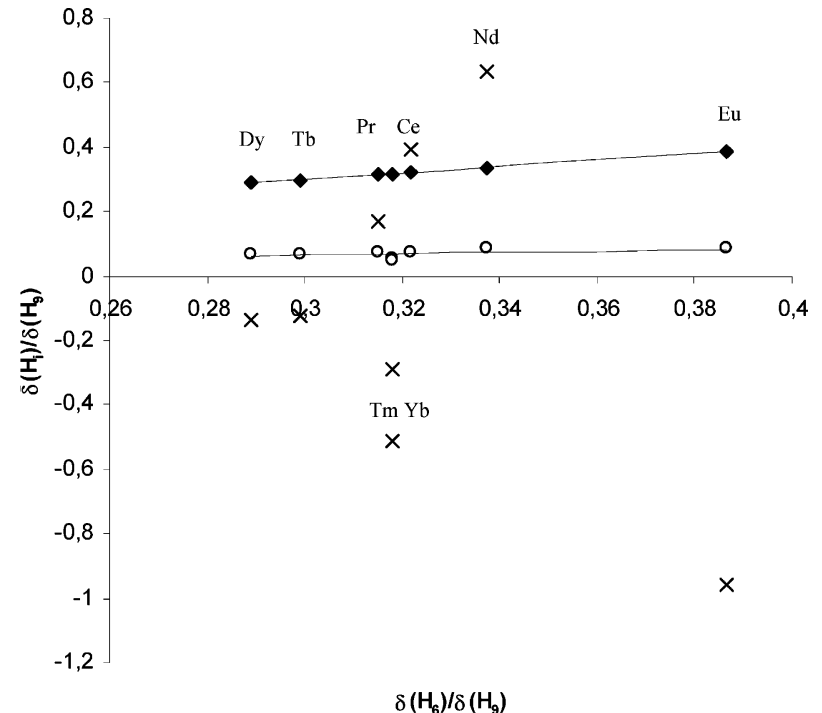

Fig. 11. ${ }^{1} \mathrm{H}$ shift ratio plots, $\delta\left(\mathrm{H}_{i}\right) / \delta\left(\mathrm{H}_{9}\right)$ vs. $\delta\left(\mathrm{H}_{6}\right) / \delta\left(\mathrm{H}_{9}\right)$ for various protons of the $\left[\operatorname{LnCo}\left(\mathrm{L}^{7}\right)_{3}\right]^{6+}\left(\mathrm{H}_{i}=\mathrm{H}_{5}(\diamond), \mathrm{H}_{10}(\square)\right.$ and $\left.\mathrm{H}_{14}(\times)\right)$.

\section{8. $\left.\left[\operatorname{Ln}(L)^{8}\right)\right]^{3+}\left(L^{8}=\right.$ azacryptand $)$}

The monometallic $\left[\mathrm{Ln}\left(\mathrm{L}_{8}\right)\left(\mathrm{NO}_{3}\right)\right]\left(\mathrm{NO}_{3}\right)_{2}$ cryptates were isolated, and their crystal structures $(\mathrm{Ln}=\mathrm{Ce}, \mathrm{Nd}$, $\mathrm{Eu}, \mathrm{Y})$ show the formation of pseudo-trigonal complexes in which the lanthanide is nine-coordinated asymmetrically at one end of the cavity, by four nitrogen atoms of one TREN tripod, three oxygen of the protonated phenols and two oxygen atoms of a bidentate nitrate, with no major structural change observed along the lanthanide series [26]. Dissolution of the complexes in $\mathrm{D}_{2} \mathrm{O}(\mathrm{pD}=5.8,298 \mathrm{~K})$ provides strict $C_{3}$-symmetry due to decomplexation of the nitrate counter-anion, as shown by the for the ${ }^{1} \mathrm{H}$ NMR data of $\left[R\left(\mathrm{~L}^{8}\right)_{3}\right]^{3+}$ $(\mathrm{R}=\mathrm{Ce}-\mathrm{Yb}$, except $\mathrm{Pm}, \mathrm{Gd})$. Plots based on Eqs. (2) and (3) display an abrupt deviation from linearity between $\mathrm{Ln}=\mathrm{Eu}$ and $\mathrm{Tb}$, requiring two different straight lines. Two different isostructural series were considered for $\mathrm{Ln}=\mathrm{Ce}-\mathrm{Tb}$ and $\mathrm{Er}-\mathrm{Yb}$, and two sets of contact $F_{i}$ and pseudo-contact $B_{0}^{2} G_{i}$ terms were obtained according to least-squares fits of Eq. (2) [26]. The simultaneous least-squares fits of lanthanide induced relaxation effects $\left(T_{1}\right)$ according to Eq. (5) and lanthanide induced shifts (LIS) according to Eq. (1) with the crystal structures of $\left[\mathrm{Ln}\left(\mathrm{L}^{8}\right)\left(\mathrm{NO}_{3}\right)\right]\left(\mathrm{NO}_{3}\right)$ led to the conclusion that no major structural change occurs in solution near the middle of the series of the $\left[\mathrm{Ln}\left(\mathrm{L}^{8}\right)_{3}\right]^{3+}$ cryptates. The breaks observed in the plots according to Eqs. (2) and (3) were thus assigned to a variation of $F_{i}$ and $B_{0}^{2}$ [26]. The application of the crystal-field independent technique (Eq. (4)) supported this statement, as two parallel straight lines corresponding to the $\mathrm{Ln}=\mathrm{Ce}-\mathrm{Eu}$ and $\mathrm{Ln}=\mathrm{Tb}-\mathrm{Yb}$ series are observed for the corresponding plots. Since the slopes correspond to $R_{i k}=G_{i} / G_{k}$, no structural change occurs near the middle of the lanthanide series, but the variations of the hyperfine constants result in different intercepts $F_{i}-F_{k} R_{i k}$ [26]. Finally, plots according to the three-nuclei method (Eq. (5)) confirm the break occurring near the middle of the series and the experimental slopes $\alpha$ and intercepts $\beta$ can be satisfactorily predicted from the $F_{i}$ terms obtained with Eqs. (2) and (3), and $R_{i k}$ terms obtained with Eq. (4) [29].

Thus, the combined application of the two-nuclei and three-nuclei techniques, together with the classical one-nucleus technique, to the complete series of $C_{3}$-axial $\mathrm{Ln}$-cryptate complexes in water, $\left[\operatorname{Ln}\left(\mathrm{L}^{8}\right)\right]^{3+}$, gave unequivocal proof of abrupt changes of the $F_{i}$ and $B_{2}^{0}$ parameters at $\mathrm{Ln}=\mathrm{Eu}-\mathrm{Tb}$, but the constancy of the geometric ratios $R_{i k}$ demonstrated the isostructurality of the whole series of complexes.

\section{9. [ $\left.\mathrm{Ln}(\mathrm{NOTA})\left(\mathrm{H}_{2} \mathrm{O}\right)_{q}\right] \mathrm{L}^{9}=1,4,7$-triazacyclononane- $N, N^{\prime}, N^{\prime \prime}$-triacetic acid, NOTA}

The triaza macrocyclic ligand $\mathrm{L}^{9}$ forms a thermodynamically quite stable series of $\left[\mathrm{Ln}(\mathrm{NOTA})\left(\mathrm{H}_{2} \mathrm{O}\right)_{q}\right]$ complexes in aqueous solution [52], but none of these has been isolated and characterized in the solid state by $\mathrm{X}$-ray crystallography. The $\mathrm{Ln}^{3+}$ induced water presup17O shifts of solutions of these complexes give evidence that their hydration number $q$ changes across the lanthanide series, from 3 to 4 in the first half $(\mathrm{Ln}=\mathrm{Ce}-$ $\mathrm{Eu})$ to 3 in the second half of the series $(\mathrm{Ln}=\mathrm{Dy}-\mathrm{Yb})$ [53]. This is supported by the fluorescence data for the $\mathrm{Eu}^{3+}$ complex in aqueous solution, where two different species are observed in equilibrium [54].

The ${ }^{1} \mathrm{H}$ and ${ }^{13} \mathrm{C} \delta_{i j}^{\text {para }}$ values for the $[\operatorname{Ln}($ NOTA) $\left(\mathrm{H}_{2} \mathrm{O}\right)_{q}$ ] complexes $(\mathrm{Ln}=\mathrm{Pr}-\mathrm{Yb}$, except $\mathrm{Pm}, \mathrm{Gd})$ in $\mathrm{D}_{2} \mathrm{O}$ (pD 6.0 and $342 \mathrm{~K}$ ) reflect the $C_{3}$ symmetry of the chelates in solution. The analysis of those shifts using Eqs. (2) and (3) gave plots with clear breaks at Tb-Dy (Fig. 12, Table 2), reflecting variations of the $F_{i}$ and $B_{0}^{2} G_{i}$ parameters [55]. It was assumed that $B_{0}^{2}$ did not change and that two groups of solution structures were present, with a change of ligand coordination number or hydration number at $\mathrm{Tb}$, leading to changes of $F_{i}$ and $G_{i}$ [55]. This hypothesis of a structural change was confirmed by simultaneous least-squares fits of lanthanide induced relaxation $\left(T_{1}\right)$ according to Eq. (5) and lanthanide induced shifts according to Eq. (1) with a chemical model of the $\left[\operatorname{Ln}(\mathrm{NOTA})\left(\mathrm{H}_{2} \mathrm{O}\right)_{q}\right]$ chelates based on modifications of the crystal structure of the $\mathrm{Cr}^{3+}$ complex. While for the later ions $(\mathrm{Ln}=\mathrm{Dy}-\mathrm{Yb})$ the ligand is hexa-coordinated with three inner-sphere water molecules, the earlier chelates $(\mathrm{Ln}=\mathrm{Pr}-\mathrm{Eu})$ adopt a structural mixture of hexa- and penta-coordinate (with one free acetate arm) ligands with three and four innersphere water molecules, respectively [55].

The application of the two-nuclei crystal-field independent technique and the three-nuclei method provides further evidence for the proposed structural subdivision 


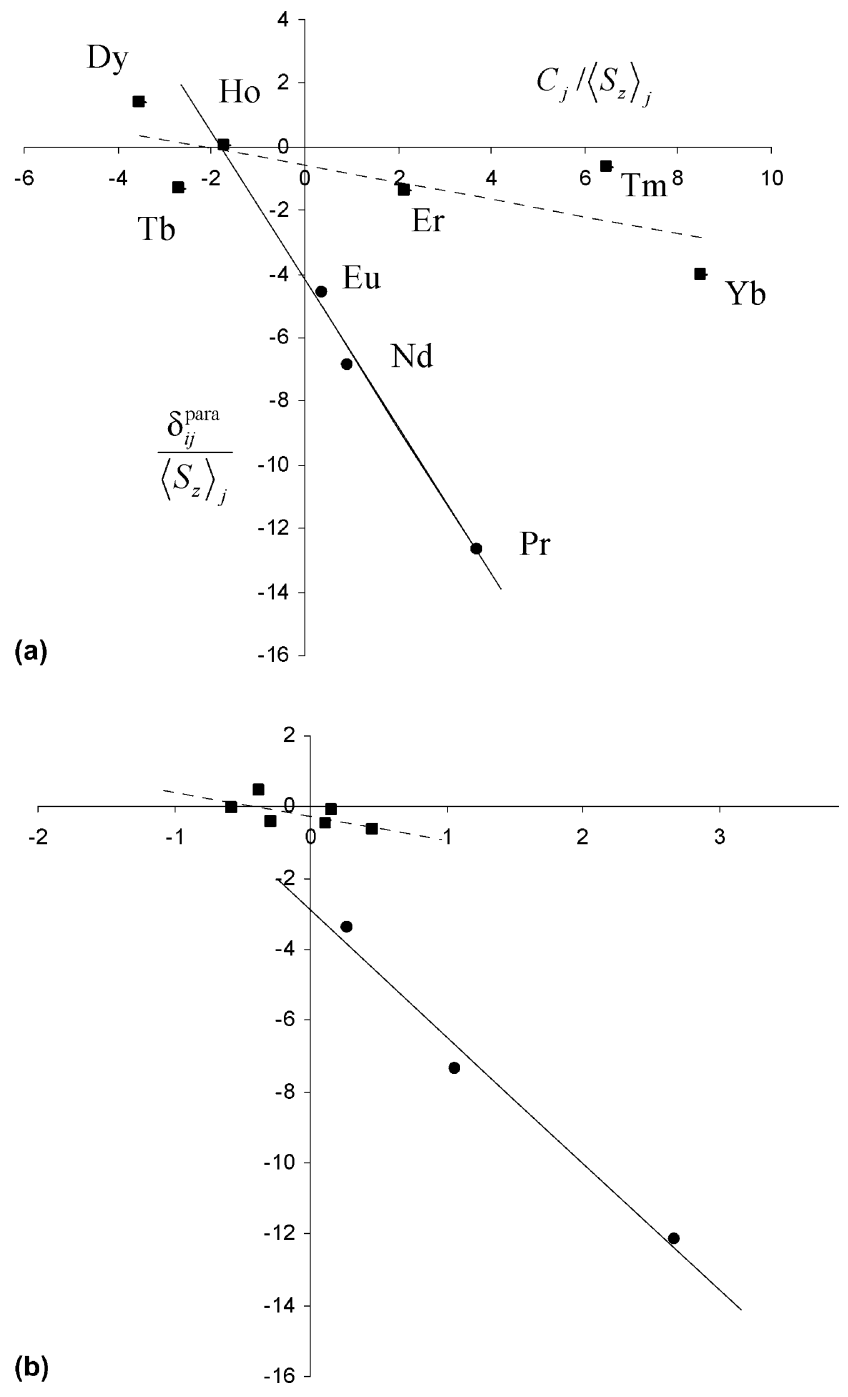

Fig. 12. Plots of (a) $\delta_{i j}^{\text {para }} /\left\langle S_{z}\right\rangle_{j}$ vs. $C_{j} /\left\langle S_{z}\right\rangle_{j}$ and (b) $\delta_{i j}^{\text {para }} / C_{j}$ vs. $\left\langle S_{z}\right\rangle_{j} / C_{j}$ for the ${ }^{13} \mathrm{C}$ nucleus at the macrocycle methylene group, $i=\mathrm{C}_{\mathrm{N}}$, for the series of $\left[\mathrm{Ln}(\mathrm{NOTA})_{3}\left(\mathrm{H}_{2} \mathrm{O}\right)_{q}\right]$ complexes $\left(\mathrm{Ln}=\mathrm{Pr}-\mathrm{Yb}, \mathrm{D}_{2} \mathrm{O}, 343 \mathrm{~K}\right)$.

of the [ $\mathrm{Ln}(\mathrm{NOTA})\left(\mathrm{H}_{2} \mathrm{O}\right)_{x}$ ] complexes [55]. All the plots of the ${ }^{1} \mathrm{H}$ and ${ }^{13} \mathrm{C}$ shifts obtained according to Eq. (4), which eliminate the effect of any changes of $B_{0}^{2}$, display two different straight lines for $\mathrm{Ln}=\mathrm{Pr}-\mathrm{Tb}$ and $\mathrm{Ln}=\mathrm{Dy}-\mathrm{Yb}$, with clear breaks at Tb-Dy (Fig. 13a), confirming that the $F_{i}$ and $G_{i}$ parameters change abruptly at $\mathrm{Tb}$. There is generally a good agreement between experimental and calculated $R_{i k}$ and $\left(F_{i}-F_{k} R_{i k}\right)$ parameters (Table 2). Also, all the shift ration plots (Eq. (5)) involving ${ }^{1} \mathrm{H}$ and ${ }^{13} \mathrm{C}$ shift ratios (Fig. 13b) confirm the abrupt break near the middle of the series. The experimental slopes $\alpha$ and intercepts $\beta$ are in satisfactory agreement with those calculated from predicted from $F_{i}$ and $G_{i}$ terms obtained from the other methods (Table 2).

Thus, the use of the two and three nuclei methods firmly supports the earlier conclusion of a change in structure between the light and heavy [Ln(NOTA)
$\left.\left(\mathrm{H}_{2} \mathrm{O}\right)_{q}\right]$ complexes. In this case, the breaks in the plots reflect a change in the geometric terms, $G_{i}$ and $F_{i}$, as they are independent of any changes of the crystal field parameter.

\section{Conclusions}

Although the classical one-nucleus crystal-field dependent method (Eqs. (2) and (3)) has met considerable success in the separation of experimental $\delta_{i j}^{\text {para }}$ values for axially symmetric lanthanide complexes into their contact and dipolar contributions, data scatter or obvious breaks in the corresponding plots are often seen for many systems $[2,5,11]$. This is particularly noticeable for large shifts, where the effect of any small difference in the crystal field parameter $B_{0}^{2}$ along the lanthanide series or deviations from the theoretical $\left\langle S_{z}\right\rangle$ and $C_{j}$ values is magnified. A decrease in $\mathrm{Ln}^{3+}$ radii along the series can result in relatively minor differences in how the $\mathrm{Ln}^{3+}$ cations bind to the ligand donor atoms, leading to small changes in the orientation of the ligands around the $\mathrm{Ln}^{3+}$. Even if this results in relatively small changes in geometry, the fact that the absolute values of $C_{j}$ for the lighter $\mathrm{Ln}^{3+}(\mathrm{Ce}-\mathrm{Eu}$ varies from 0.7-11) are smaller than those of the heavier $\mathrm{Ln}^{3+}(\mathrm{Tb}-\mathrm{Yb}$ varies from 22 to 100), magnifies the effect of any small changes in $G_{i}$ when using Eq. (3) [25]. The resulting large statistical errors in $F_{i}$ and $B_{0}^{2} G_{i}$ values obtained by the method often preclude any reliable quantitative study of the structural and bonding properties of the respective lanthanide complexes. In particular, these crystal-field dependent cannot be used for detecting structural $G_{i}$ changes because any variation of the crystal-field parameter $B_{0}^{2}$ along the lanthanide series affects the $B_{0}^{2} G_{i}$ term.

The two-nuclei technique (Eq. (4)), which it is independent of the crystal-field parameter $B_{0}^{2}$, is very useful as a reliable method to study the isostructurality of a series of lanthanide complexes [25-27,30-32]. The linearity of the corresponding experimental plots is a proof of isostructurality of the complexes, due to the constancy of their slopes $R_{i k}=\left(G_{i} / G_{k}\right)$ and intercepts $\left(F_{i}-F_{k} R_{i k}\right)$, and therefore of the geometric terms $G_{i}$ and hyperfine coupling constants $F_{i}$. When a break occurs in those plots, the two lines may be parallel, which indicates that no major geometric change occurs (constant slopes) but variations of $F_{i}$ values result in different intercepts $\left(F_{i}-F_{k} R_{i k}\right)$, or not when a structural change affects both $G_{i}$ and $F_{i}$ values. The combined use of the the one- and two-nuclei techniques allows to conclude it the changes of $B_{0}^{2} G_{i}$ demonstrated by breaks of plots using the first method result from changes of $B_{0}^{2}, G_{i}$ or both.

The main advantage of the three nuclei shift ratio method (Eq. (5)) [29] for analyzing the isostructurality 
Table 2

Comparison of parameters for $\left[\mathrm{Ln}(\mathrm{NOTA})\left(\mathrm{H}_{2} \mathrm{O}\right)_{q}\right]$ obtained directly using the graphical methods based on Eqs. 4 and 5 and indirectly using the parameters $F_{i}$ and $B_{2}^{0}$ obtained from Eq. (2)

\begin{tabular}{|c|c|c|c|c|c|c|}
\hline \multirow[t]{2}{*}{ Nuclei } & \multicolumn{3}{|l|}{$\mathrm{Ce}-\mathrm{Tb}$} & \multicolumn{3}{|l|}{$\mathrm{Dy}-\mathrm{Yb}$} \\
\hline & $F_{i}$ & $B_{2}^{0}$ & $R^{2}$ & $F_{i}$ & $B_{2}^{0}$ & $R^{2}$ \\
\hline$C_{\mathrm{o}}$ & 3.19 & 3.37 & 0.999 & -4.15 & 2.06 & 0.914 \\
\hline$C_{\mathrm{a}}$ & 2.37 & 0.30 & 0.881 & -3.00 & 0.33 & 0.704 \\
\hline$C_{N}$ & -4.15 & -2.32 & 0.985 & -0.58 & -0.27 & 0.552 \\
\hline$H_{\mathrm{a}}$ & 0.37 & -0.12 & 0.914 & 0.75 & 0.04 & 0.799 \\
\hline$H_{N^{\prime}}$ & 0.36 & -0.23 & 0.704 & 0.15 & -0.08 & 0.730 \\
\hline$H_{N^{\prime \prime}}$ & 0.38 & -1.18 & 0.552 & 0.97 & -0.43 & 0.905 \\
\hline$i=C_{N} ; k=C_{\mathrm{o}}$ & $R_{i k}$ & $F_{i}-R_{i k} F_{k}$ & $R^{2}$ & $R_{i k}$ & $F_{i}-R_{i k} F_{k}$ & $R^{2}$ \\
\hline$(\exp )$ & -0.69 & -6.35 & 0.976 & -0.17 & -0.90 & 0.901 \\
\hline (calc) & -0.69 & -6.32 & & -0.13 & -1.12 & \\
\hline \multicolumn{7}{|l|}{$i=C_{\mathrm{a}} ; k=C_{\mathrm{o}}$} \\
\hline$(\exp )$ & 0.11 & -2.18 & 0.917 & 0.18 & -2.42 & 0.937 \\
\hline (calc) & 0.09 & -2.09 & & 0.16 & -2.34 & \\
\hline \multicolumn{7}{|l|}{$i=C_{\mathrm{a}} ; k=C_{N}$} \\
\hline$(\exp )$ & 0.16 & -3.18 & 0.958 & 1.05 & -3.36 & 0.958 \\
\hline (calc) & 0.13 & -2.91 & & 1.22 & -3.71 & \\
\hline \multicolumn{7}{|l|}{$i=H_{N^{\prime}} ; k=H_{\mathrm{a}}$} \\
\hline$(\exp )$ & 1.02 & -0.13 & 0.956 & 0.22 & 0.36 & 0.908 \\
\hline (calc) & 1.92 & -0.35 & & 2.00 & 1.65 & \\
\hline \multicolumn{7}{|l|}{$i=H_{N^{\prime}} ; k=H_{N^{\prime \prime}}$} \\
\hline$(\exp )$ & 0.15 & 0.25 & 0.991 & 0.05 & -0.11 & 0.953 \\
\hline (calc) & 0.20 & 0.28 & & 0.19 & -0.14 & \\
\hline \multicolumn{7}{|l|}{$i=H_{N^{\prime \prime}} ; k=H_{\mathrm{a}}$} \\
\hline$(\exp )$ & 7.35 & -2.62 & 0.970 & 3.71 & 3.87 & 0.962 \\
\hline (calc) & 9.83 & -3.26 & & 10.75 & 8.99 & \\
\hline \multirow{3}{*}{$\begin{array}{l}i=C_{N} ; k=C_{\mathrm{a}} ; l=C_{\mathrm{o}} \\
\quad(\exp ) \\
\quad(\text { calc) }\end{array}$} & $\alpha$ & $\beta$ & $R^{2}$ & $\alpha$ & $\beta$ & $R^{2}$ \\
\hline & -0.968 & 2.961 & 0.981 & 0.244 & 0.311 & 0.960 \\
\hline & -1.379 & 2.985 & & -0.210 & 0.396 & \\
\hline \multicolumn{7}{|l|}{$i=H_{N^{\prime \prime}} ; k=H_{\mathrm{a}} ; \quad l=H_{N^{\prime}}$} \\
\hline$(\exp )$ & 16.76 & -10.43 & 0.865 & 16.05 & -1.58 & 0.961 \\
\hline (calc) & 9.33 & 8.72 & & 5.65 & -6.39 & \\
\hline
\end{tabular}

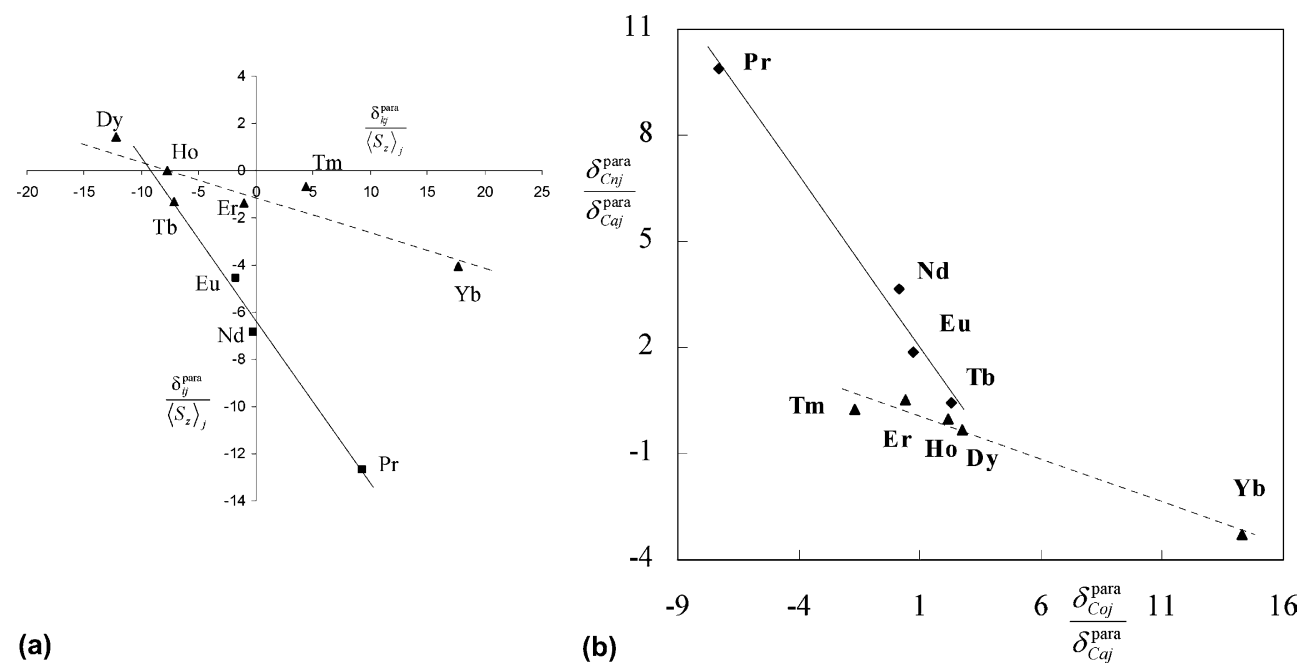

Fig. 13. (a) Plot of $\delta_{i j}^{\text {para }} /\left\langle S_{z}\right\rangle_{j}$ vs. $\delta_{k j}^{\text {para }} /\left\langle S_{z}\right\rangle_{j}$ for the $i=\mathrm{C}_{\mathrm{N}}$ and $k=\mathrm{C}_{\mathrm{o}}$ (carboxylate) ${ }^{13} \mathrm{C}$ pair of nuclei, and (b) Shift ratio plot for the ${ }^{13} \mathrm{C}$ triad of nuclei $\mathrm{C}_{\mathrm{N}}, \mathrm{C}_{\mathrm{a}}$ (acetate arm methylene), $\mathrm{C}_{\mathrm{o}}, \delta\left(\mathrm{C}_{\mathrm{o}}\right) / \delta\left(\mathrm{C}_{\mathrm{a}}\right)$ vs. $\delta\left(\mathrm{C}_{\mathrm{o}}\right) / \delta\left(\mathrm{C}_{\mathrm{a}}\right)$, both for the series of $\left[\mathrm{Ln}(\mathrm{NOTA})_{3}\left(\mathrm{H}_{2} \mathrm{O}\right)_{q}\right]$ complexes $\left(\mathrm{Ln}=\mathrm{Pr}-\mathrm{Yb}, \mathrm{D}_{2} \mathrm{O}\right.$, $343 \mathrm{~K})$.

of lanthanide complexes is that it is based exclusively on the experimental shift data, and since it requires no knowledge of $B_{0}^{2},\left\langle S_{z}\right\rangle$ or $C_{j}$ values, any uncertainty or small variations in these parameters are eliminated as possible sources of error. It can be applied to the shift data measured at any temperature, as long as the data 
are available for at least three nuclei within a given ligand. Its value for analyzing the isostructurality of lanthanide complexes, together with the two nuclei method, has been demonstrated in this work using the $\delta_{i j}^{\text {para }}$ data reported in literature for slow-exchanging complexes of a variety of ligands with different charge, size, coordination stoichiometry and aromaticity, in different solvents and temperatures.

The main disadvantage of this method is that the slopes $\alpha$ and intercepts $\beta$ of plots according to Eq. (5) are complicated functions of $F_{i}$ and $G_{i}$ ratios rather than of their values, which may reduce or magnify in some cases the effects of $\mathrm{Ln}^{3+}$ contraction on $F_{i}$ and $G_{i}$ parameters. The method does not provide quantitative values for $F_{i}$ and $G_{i}$, as demonstrated by Eq. (7) (another form of Eq. (5)), it is impossible to obtain the four unknowns $\left(F_{i k}, F_{l k}, R_{i k}, R_{l k}\right)$ simultaneously, using only three paramegnetic shift values $\left(\delta_{i}, \delta_{k}, \delta_{l}\right)$

$\left(F_{l k}-R_{l k}\right) \delta_{i}=\left(F_{i k}-R_{i k}\right) \delta_{l}+\left(F_{l k} R_{i k}-F_{i k} R_{l k}\right) \delta_{k}$,

where $F_{i k}=\left(F_{i} / F_{k}\right)$ and $F_{l k}=\left(F_{l} / F_{k}\right)$. The experimental values of the $\alpha$ and $\beta$ coefficients can be used as a valuable check of the $F_{i}$ and $G_{i}$ values obtained by the one- and two-nuclei methods.

The combined use of Eqs. (2)-(5) provides new insights in the structural analysis of lanthanide complexes, as demonstrated in the present study. Isostructurality of the whole series of lanthanide complexes, with no change of the $F_{i}, G_{i}$ and $B_{0}^{2}$ parameters, is proven for the complexes of $\mathrm{L}^{5}\left(\left[\left(\operatorname{Ln}(\mathrm{BBZP})_{3}\right]^{3+}\right)\right)$ and $\mathrm{L}^{6}\left(\left[\mathrm{Ln}(\text { terpy })_{3}\right.\right.$ $\left.\left.\left(\mathrm{CF}_{3} \mathrm{SO}_{3}\right)_{3}\right]\right)$ using the one-nucleus and two-nuclei methods. The three-nuclei method supports such an isostructurality for the later complexes, but, due to a high sensitivity of the $\alpha$ and $\beta$ parameters, it detects a small structural change in the $\mathrm{Tb}$ and Dy complexes of $\mathrm{L}^{5}$ relative to the early $(\mathrm{Ce}-\mathrm{Eu})$ series. Isostructurality is sometimes found in a series of lanthanide complexes, with changes of the $F_{i}$ and $B_{0}^{2}$ parameters, using the combination of the two first methods, like in the complexes of $\mathrm{L}^{7}\left(\left[\mathrm{LnCo}\left(\mathrm{L}^{7}\right)_{3}\right]^{6+}\right.$ and $\left[\mathrm{LnCo}\left(\mathrm{L}^{7}\right)_{3}\right]^{5+}$ binuclear helicates), and $\mathrm{L}^{8}\left(\left[\operatorname{Ln}\left(\mathrm{L}^{8}\right)\right]^{3+}\right.$ cryptates). Again, the three-nuclei method supports the overall isostructurality for the later complexes, but detects small structural changes in the helicate complexes of $\mathrm{L}^{7}$ along the series. Clearer changes involving the three parameters, $F_{i}, G_{i}$ and $B_{0}^{2}$, are observed in many series of complexes, such as those of $\mathrm{L}^{1}\left(\left[\mathrm{Ln}(\mathrm{GLYC})_{3}\left(\mathrm{H}_{2} \mathrm{O}\right)_{q}\right]\right), \mathrm{L}^{2}$ $\left(\left[\operatorname{Ln}(\mathrm{ODA})_{3}\right]^{3-}\right), \mathrm{L}^{3}\left(\left[\operatorname{Ln}(\mathrm{PDCA})_{3}\right]^{3-}\right), \mathrm{L}^{4}\left(\left[\operatorname{Ln}\left(\mathrm{L}^{4}\right)_{3}\right]^{3+}\right)$ and $\mathrm{L}^{9}\left(\left[\mathrm{Ln}(\mathrm{NOTA})\left(\mathrm{H}_{2} \mathrm{O}\right)_{q}\right]\right)$, where there is agreement of the data analysis by the three methods. These structural changes are sometimes associated with changes of hydration numbers and/or carboxylate oxygen coordination (like for $\mathrm{L}^{9}$ ). More subtle changes involving the internal dynamics of the bound ligands are proposed in other cases $\left(\mathrm{L}^{1}, \mathrm{~L}^{2}, \mathrm{~L}^{3}\right.$ and $\left.\mathrm{L}^{4}\right)$ on the basis of the present graphical analysis. However, specially in these cases, we cannot discard the possibility that the data plots used result in a magnification of the breaks that should be normally expected due to gradual changes in the structure due to the decrease of the ionic radius along the $\mathrm{Ln}$ series [21]. This is particularly true for very structure-sensitive nuclei with theta angles near the magic angle, where small angle changes have relatively large effects. This would cause the appearance of breaks on NMR data plots in cases where the complexes are found to be nearly isostructural in the solid state.

\section{Acknowledgements}

We thank Dr. J. Peters for useful discussions. Support of this research by grants from the Robert A. Welch Foundation (AT-584), the NIH Biotechnology Research Program (RR02584) and Fundação da Ciência e Tecnologia, Portugal (PRAXIS 2/2.1/SAU/1194/96) is gratefully acknowledged.

\section{References}

[1] (a) C.F.G.C. Geraldes, in: M. Pons (Ed.), NMR in Supramolecular Chemistry, Kluwer Academic Publishers, Amsterdam, 1999, p. 133;

(b) I. Bertini, M.B.L. Janik, Y.-M. Lee, C. Luchinat, A. Rosato, J. Am. Chem. Soc. 123 (2001) 4181.

[2] (a) I. Bertini, C. Luchinat, Coord. Chem. Rev. 150 (1996) 1; (b) J.A. Peters, J. Huskens, D.J. Raber, Prog. NMR Spectrosc. 28 (1996) 283;

(c) J.H. Forsberg, in: K.A. Gschneidner, L. Eyring (Eds.), Handbook on the Physics and Chemistry of Rare Earths, vol. 23, Elsevier, Amsterdam, 1996, p. 1 (Chapter 153).

[3] (a) P.D. Burns, G.N. La Mar, J. Magn. Reson. 46 (1982) 61; (b) S. Aime, L. Barbero, M. Botta, G. Ermondi, J. Chem. Soc., Dalton Trans. (1992) 225.

[4] (a) P. Caravan, J.J. Ellison, T.J. McMurry, R.B. Lauffer, Chem. Rev. 99 (1999) 2293;

(b) É. Tóth, L. Helm, A.E. Merbach, in: A.E. Merbach, É. Tóth (Eds.), The Chemistry of Contrast Agents in Medical Magnetic Resonance Imaging, Wiley, Chichester, 2001, p. 45.

[5] (a) J.A. Peters, E. Zitha-Bovens, D.M. Corsi, C.F.G.C. Geraldes, in: A.E. Merbach, É. Tóth (Eds.), The Chemistry of Contrast Agents in Medical Magnetic Resonance Imaging, Wiley, Chichester, 2001, p. 315;

(b) L. Frullano, J. Rohovec, J.A. Peters, C.F.G.C. Geraldes, Top. Curr. Chem. 221 (2002) 26.

[6] (a) D.J. Raber, in: Lanthanide Shift Reagents in Stereochemical Analysis, VCH Publishers Inc., New York, 1983 (Chapter 6); (b) M.S. Nieuwenhuizen, J.A. Peters, A. Sinnema, A.P.G. Kieboom, H. van Bekkum, J. Am. Chem. Soc. 107 (1985) 12.

[7] (a) J. Reuben, J.C.S. Dalton Trans. (1979) 68;

(b) J.A. Peters, C.A.M. Vijverberg, A.P.G. Kieboom, H. van Bekkum, Tetrahedron Lett. 24 (1983) 3141.

[8] C.C. Hinckley, J. Am. Chem. Soc. 91 (1969) 5160.

[9] (a) D.C. Buster, M.M.C.A. Castro, C.F.G.C. Geraldes, C.R. Malloy, A.D. Sherry, T.C. Siemers, Magn. Reson. Med. 15 (1990) 25; (b) C.R. Malloy, D.C. Buster, M.M.C.A. Castro, C.F.G.C. Geraldes, F.M.H. Jeffrey, A.D. Sherry, Magn. Reson. Med. 15 (1990) 33. 
[10] M.C. Alpoim, A.M. Urbano, C.F.G.C. Geraldes, J.A. Peters, J. Chem. Soc., Dalton Trans. (1992) 463.

[11] (a) J.A. Peters, A.P.G. Kieboom, Recl. Trav. Chim. Pays-Bas 102 (1983) 381 ;

(b) C.F.G.C. Geraldes, A.D. Sherry, J. Magn. Reson. 66 (1985) 274.

[12] (a) S. Aime, M. Botta, M. Fasano, E. Terreno, P. Kinchesh, L. Calabi, L. Paleari, Magn. Reson. Med. 35 (1996) 648;

(b) C.S. Zuo, K.R. Metz, Y. Sun, A.D. Sherry, J. Magn. Reson. 133 (1998) 53;

(c) M. Henschel, M. Findeisen, W. Schmidt, T. Frenzel, W. Wlodarczyk, P. Wust, R. Felix, Magn. Reson. Mater. Phys., Biol. Med. 10 (2000) 52.

[13] R.M. Golding, M.P. Halton, Aust. J. Chem. 25 (1972) 2577.

[14] B. Bleaney, J. Magn. Reson. 8 (1972) 91

[15] A.A. Pinkerton, M. Rossier, S. Spiliadis, J. Magn. Reson. 64 (1985) 420.

[16] W. de, W. Horrocks Jr., J.P. Sipe III, Science 177 (1972) 994.

[17] B.R. McGarvey, J. Magn. Reson. 33 (1979) 445.

[18] J.M. Briggs, G.P. Moss, E.W. Randall, K.D. Sales, J. Chem. Soc., Chem. Commun. (1972) 1180.

[19] C.N. Reilley, B.W. Good, J.F. Desreux, Anal. Chem. 47 (1975) 2110

[20] R.M. Golding, P. Pyykkö, Mol. Phys. 26 (1973) 1389.

[21] J.A. Peters, J. Magn. Reson. 68 (1986) 240.

[22] J. Reuben, J. Magn. Reson. 50 (1982) 233.

[23] J. Ren, A.D. Sherry, J. Magn. Reson. B 111 (1996) 178.

[24] J. Lisowski, J.L. Sessler, V. Lynch, T.D. Mody, J. Am. Chem. Soc. 117 (1995) 2273

[25] S. Spiliadis, A.A. Pinkerton, J. Chem. Soc., Dalton Trans. (1982) 1815.

[26] C. Platas, F. Avecilla, A. de Blas, C.F.G.C. Geraldes, T. RodriguezBlas, H. Adams, J. Mahia, Inorg. Chem. 38 (1999) 3190.

[27] J. Ren, S. Zhang, A.D. Sherry, C.F.G.C. Geraldes, Inorg. Chim. Acta 339 (2002) 273-282.

[28] W. de, W. Horrocks Jr., J. Magn. Reson. 26 (1977) 333.

[29] C.F.C.G. Geraldes, S. Zhang, C. Platas, T. Rodriguez-Blas, A. de Blas, A.D. Sherry, J. Alloys Compds. 323/324 (2001) 824

[30] N. Ouali, B. Bocquet, S. Rigault, P.-Y. Morgantini, J. Weber, C. Piguet, Inorg. Chem. 41 (2002) 1436.

[31] (a) S. Rigault, C. Piguet, J. Am. Chem. Soc. 122 (2000) 9304; (b) S. Rigault, C. Piguet, J.-C.G. Bünzli, J. Chem. Soc., Dalton Trans. (2000) 2045.

[32] S. Rigault, C. Piguet, G. Bernardinelli, G. Hopfgartner, J. Chem. Soc., Dalton Trans. (2000) 4587.
[33] A.E. Martell, R.M. Smith, in: Critical Stability Constants, vol. 3, Plenum Press, New York, 1977, p. 134.

[34] J.A. Peters, M.S. Nieuwenhuizen, A.P.G. Kieboom, D.J. Raber, J. Chem. Soc., Dalton Trans. (1988) 717.

[35] C.A.M. Vijverberg, J.A. Peters, A.P.G. Kieboom, H. van Bekkum, Recl. Trav. Chim. Pays-Bas 99 (1980) 403.

[36] C.A.M. Vijverberg, J.A. Peters, A.P.G. Kieboom, H. van Bekkum, Tetrahedron 42 (1980) 167.

[37] J.A. Peters, J. Chem. Soc., Dalton Trans. (1988) 961.

[38] T.A. Hopkins, D.H. Metcalf, F.S. Richardson, Inorg. Chem. 37 (1998) 1401

[39] T.A. Hopkins, J.P. Bolender, D.H. Metcalf, F.S. Richardson, Inorg. Chem. 35 (1996) 5356.

[40] J.M. Harrowfield, Y. Kim, B.W. Skelton, A.H. White, Aust. J. Chem. 48 (1995) 807.

[41] B.M. Alsaadi, F.J.C. Rossotti, R.J.P. Williams, J. Chem. Soc., Dalton Trans. (1980) 597.

[42] H. Donato, R.B. Martin, J. Am. Chem. Soc. 94 (1972) 4129.

[43] F. Renaud, C. Piguet, G. Bernardinelli, J.-C.G. Bünzli, G. Hopfgartner, Chem. Eur. J. 3 (1997) 1646.

[44] C. Piguet, C.F.G.C. Geraldes, in: K.A. Gschneidner, L. Eyring (Eds.), Handbook on the Physics and Chemistry of Rare Earths, vol. 33, Elsevier, Amsterdam, 2003, pp. 353-463, Chapt. 215.

[45] C. Piguet, J.-C.G. Bünzli, G. Bernardinelli, A.F. Williams, Inorg. Chem. 32 (1993) 4139

[46] S. Petoud, J.-C.G. Bünzli, F. Renaud, C. Piguet, K.J. Schenk, G. Hopfgartner, Inorg. Chem. 36 (1997) 5750.

[47] J.H. Forsberg, M.J. Forsberg, D.E. Schwarz, Abstract of the 21s Rare Earth Research Conference, Duluth, Minnesota, July 7-12, 1996.

[48] J.H. Forsberg, R.M. Delaney, Q. Zhao, G. Harakas, R. Chandran, Inorg. Chem. 34 (1995) 3705.

[49] C. Piguet, C. Edder, S. Rigault, G. Bernardinelli, J.-C.G. Bünzli, G. Hopfgartner, J. Chem. Soc., Dalton Trans. (2000) 3999.

[50] C. Piguet, J.-C.G. Bünzli, G. Bernardinelli, G. Hopfgartner, S. Petoud, O. Schaad, J. Am. Chem. Soc. 118 (1996) 6681.

[51] S. Rigault, C. Piguet, G. Bernardinelli, G. Hopfgartner, Angew. Chem. Int. Ed. Engl. 37 (1998) 169.

[52] W.P. Cacheris, S.K. Nickle, A.D. Sherry, Inorg. Chem. 26 (1987) 958.

[53] C.C. Bryden, C.N. Reilley, J.F. Desreux, Anal. Chem. 53 (1981) 1418.

[54] C.C. Bryden, C.N. Reilley, Anal. Chem. 54 (1982) 610

[55] A.D. Sherry, M. Singh, C.F.G.C. Geraldes, J. Magn. Reson. 66 (1986) 511 